\title{
Measuring Organizational Learning
}

by

Lorraine S. Nemeth

Faculty of Education

Submitted in partial fulfilment

of the requirements for the degree of

Master of Education

Faculty of Graduate Studies

The University of Western Ontario

London, Ontario

March 1997

Copyright: Lorraine S. Nemeth 1997 
National Library

of Canada

Acquisitions and

Bibliographic Services

395 Wellington Street

Ottawa ON K1A ONA

Canada
Bibliothèque nationale

du Canada

Acquisitions et

services bibliographiques

395. ne Wellington

Otawa ON K1A ON4

Canada your ste volese newrence

Our sis Nome riveresce
The author has granted a nonexclusive licence allowing the National Library of Canada to reproduce, loan, distribute or sell copies of his/her thesis by any means and in any form or format, making this thesis available to interested persons.

The author retains ownership of the copyright in his/her thesis. Neither the thesis nor substantial extracts from it may be printed or otherwise reproduced with the author's permission.
L'auteur a accordé une licence non exclusive permettant à la Bibliothèque nationale du Canada de reproduire, prêter, distribuer ou vendre des copies de sa thèse de quelque manière et sous quelque forme que ce soit pour mettre des exemplaires de cette thèse à la disposition des personnes intéressées.

L'auteur conserve la propriété du droit d'auteur qui protège sa thèse. $\mathrm{Ni}$ la thèse ni des extraits substantiels de celle-ci ne doivent être imprimés ou autrement reproduits sans son autorisation.

\section{Canadằ}




\section{Abstract}

The growing body of Organizational Learning (OL) research introduces a perspective that learning is not only the capability of individuals; learning can also happen on a group level and is facilitated by an organizational climate that provides the conditions and motivation for learning. This perspective challenges educators to accept a broad definition of individual learning and also challenges us to understand learning as a group and organizational level phenomenon. The thesis of the research was that educators can benefit from developing a pragmatic knowledge of $\mathrm{OL}$ and that a measurement instrument can be a catalyst to helping us understand how to improve organizational effectiveness through better learning processes and abilities. The paper includes an extensive theoretical discussion of $\mathrm{OL}$ and the analysis of results from applying an instrument that can help diagnose perceptions of existing learning patterns and beliefs about learning in organizations. The theoretical discussion and empirical results were highly suggestive that $\mathrm{OL}$ is more than the learning that individuals do and that the $\mathrm{OL}$ research provides valuable insights for educators. The ability to measure perceptions of learning patterns provides data that can add to our understanding of how to invest resources to improve organizational effectiveness through improved learning patterns.

Keywords: Organizational Learning, Leaming Assessment tool, Learning Patterns, Learning Organization, Training and Development. 


\section{Table of Contents}

Certificate of Examination

Page

Abstract

ii

iii

Table of Contents

iv

One: Introduction

1

Two: Literature Review

7

Three: Theoretical Framework

41

Four: Research Procedures

Five: Results

Six: Conclusions

Appendices

Appendix 1: Learning Assessment Map

Evidence of Ethical Approval 106

Bibliography 107

Vita 


\section{Introduction}

Within the last decade, corporate educators have been introduced to the idea of facilitating and managing organizational learning $(\mathrm{OL})$ as one way to help their organizations remain competitive. Business writers talk about an organization's ability to learn as a key requirement for innovation and strategic renewal. A recent Conference Board of Canada publication states:

For organizations in the 1990s, learning makes the critical difference. Through learning, organizations adapt to environmental constraints, avoid the repetition of past mistakes and retain critical knowledge that might otherwise be lost... As the rate of learning becomes a more critical element in gaining competitive advantage, it is generally recognized that organizations must become more "intentional" about their own learning processes.....Many of the critical problems our organizations face are problems of learning. The ability to implement a strategic change, to respond to a competitive challenge, to move critical knowledge across divisional boundaries - all are closely tied to the organization's ability to learn. (Dixon, 1993, p.3)

As an educator in a corporate Learning and Development division, I began exploratory research into organizational learning to find evidence of a need for organizations to take a broad look at learning and understand organizational learning. Initially, I turned to scholarly work on the subject and found a broad body of literature that convincingly argued the need to understand and execute organizational learning. 
The growing body of $\mathrm{OL}$ research introduces a perspective that learning is not only the capability of individuals; learning can also happen on a group level and is facilitated by an organizational climate that provides the conditions and motivation for learning. This perspective challenges educators to accept a broad definition of individual learning and also challenges us to understand learning as a group and organizational level phenomenon.

In education, whether it is public, private, or corporate education, we are primarily concerned with developing the knowledge, skills, attitudes and values of individuals. The development of knowledge and skills usually takes place through planned, programmed instruction and is assessed on an individual basis. Scheffler (1973) states, "the goal of education should be nothing short of the fullest possible development of the human organism....educational theory starts from this fact.... (including) goals such as (developing) individuality, imagination, integrity, autonomy and sensitivity." (p.167) Learning is most commonly understood to be a deliberate effort to increase one's knowledge and cognitive ability or to consciously change behaviour. Individuals come into a learning environment, instructional activity takes place, and the knowledge gained is measured through some type of assessment on an individual basis. Often learning is conceptualized as a transfer of knowledge from an expert (teacher) to the learner (student). Events such as taking a course at school, using a self-learning book to learn a new software program, and practicing a golf swing are examples of this type of learning. Educators have at our disposal, a vast and growing body of knowledge about the development of the skills and abilities of individuals in educational settings. The OL 
literature is less concerned with learning events and focuses on learning that can take place daily as people are faced with unfamiliar situations and information, interact with other people, problem-solve, and respond to daily events. The emphasis is on learning that involves consciaus and unconscious change and learning that may or may not be intentional, observable or measurable. In OL theories, learning is also not necessarily only an expectation of individuals. Dixon's (1993) description of learning and work helps to illustrate the perspective on learning held by organizational learning theorists:

We normally think of learning and work as separate activities... learning is frequently a part of the task itself. Most jobs now require interpreting, analysing and synthesizing information, tasks that were formerly expected only of managers... The terms interpretation, analysis and synthesis, which are often used to describe the new work, are aspects of learning; thus learning and work have become synonymous terms. Rather than learn in preparation for work, employees must learn their way out of the work problems they address. ... the behaviours that define learning and the behaviours that define being productive are one and the same. (p. 3)

In order for educators to leverage this perspective to increase the effectiveness of our organizations, we need to develop the ability to do three things: first, we need to be able to visualize our organizations as learning organizations. This requires us to challenge our beliefs about learning and develop skills and knowledge to recognize and describe how our own organizations would function as learning organizations. Second, we need to 
be able to diagnose and describe the learning processes and capabilities that currently exist in our organizations. Finally, we need to develop methods and abilities to close the gap between where the organization is today and where it needs to be as a learning organization. This research provides insights that can be used by educators to expand our repertoire of educational practices and perform these three functions.

The thesis of the research is that educators can benefit from developing a pragmatic knowledge of organizational learning and that a measurement instrument can be a catalyst to helping us understand how to improve organizational effectiveness through better learning processes and abilities. Two research questions support the study:

1. What is the difference between organizational learning and the learning of individuals who are participants in the organization?

2. If we can substantiate organizational learning theoretically, can it be identified, diagnosed and leveraged?

The research involves an extensive literature review and an analysis of a framework for organizational learning. The research then goes beyond the theoretical treatment to apply an instrument that may help diagnose perceptions of existing learning patterns and beliefs about learning in our organizations. The analysis of information gathered with the measurement instrument can help to identify points of intervention to help close the gap between how the organization functions today and how it could function with improved learning abilities. The use of the instrument, which is 
currently in formative stages, allows us to assess its utility to provide insight into the value- added, to educators, of $O L$ research.

The measurement instrument used in this study is called the "Learning Assessment Map". It is one of eighteen assessment instruments described by Van Buren and Lucadamo (1996) in a recent American Society for Training and Development (ASTD) survey of learning organization assessment instruments. The Learning Assessment Map has been developed on a foundation of a decade of research by a group of researchers at the Richard Ivey School of Business at the University of Western Ontario. The instrument has demonstrated strong reliability and validity in terms of measuring perceptions of learning patterns on three levels: individual, group, and organization. It reveals differences in learning at the three levels, flows of information between the levels and differences in learning cognition and behaviours. Some of the questions the instrument helps to answer are:

1. How well developed is each level of learning in the organization?

2. Are the current patterns of learning bringing the results we need?

3. Do our employees believe that our organizational culture facilitates learning?

4. Is new knowledge institutionalized?

5. Are systemic organizational elements seen to be blocking the learning of individuals and groups?

6. How can we leverage the resources available to enhance our organizational learning? 
The Learning Assessment Map was selected for use in this study for three reasons; first, it was the only instrument inventoried by the ASTD that can provide results of tests to show reliability and validity of the instrument; second, the opportunity was available to work directly with the experts developing it; and third, it is built on a robust conceptual framework. The conceptual framework helps us to create a unique vision of our organizations as learning organizations. In this research, the Learning Assessment Map is used to investigate the perceived learning patterns and cognition in a service organization with 175 employees.

The research document includes six chapters. In chapter two, a review of literature is presented and discussed in the context of creating models of performance for learning organizations. In chapter three, the Learning Matrix is presented. Chapter four covers the procedures followed to apply the measurement instrument and chapter five presents the analysis and interpretation of results. Finally, in chapter six, conclusions are drawn about the necessity of educators to pay attention to Organizational Learning and the utility of the measurement instrument for helping us to operationalize $\mathrm{OL}$. 


\section{Chapter Two: Literature Review}

The goal of the literature review is to provide an understanding of the knowledge required to articulate a vision for our organizations as learning organizations. The review begins with a look at selected definitions of organizational learning (Table 1.1).

\section{Table 1.1 Definitions of Organizational Learning}

Learning Organizations are organizations where people continually expand their capacity to create the results they truly desire, where new and expansive patterns of thinking are nurtured, where collective aspirations are set free and where people are continually learning how to learn together. (Senge, 1990, p.3)

A Leaming Company is an organization that facilitates the learning of all its members and continuously transforms itself. (Pedler, Burgoyne and Boydell, 1991, p.12)

Organizational Learning is a process in which members of an organization detect errors or anomalies and correct it by restructuring organizational theory of action, embedding the results of their inquiry in organizational maps and images. (Argyris, 1977, pl16.)

A Learning Organization is an organization skilled in creating, acquiring and transferring knowledge, and at modifying its behaviour to reflect new knowledge and insights. (Garvin, 1993, p.80)

The capacity or processes within an organization to maintain or improve performance based on experience. (Nevis, 1995, p.73)

Organizational Learning means the process of improving actions through better knowledge and understanding. (Fiol and Lyles, 1985, p.803)

Organizations are seen as learning by encoding inferences from history into routines that guide behaviour. (Levitt and March, 1988, p. 319)

Organizational Learning is a process by which knowledge about action outcome relationships between the organization and the environment is developed. (Daft and Weick, 1984, p.285) 
There are some common themes in the set of definitions in Table 1.1: new knowledge can improve performance, learning needs to be shared with all who can take advantage of it, a changing environment necessitates learning, and OL can facilitate change and improved performance. Some researchers define the phenomenon as a continuous process and use the terms "Organizational Learning" and "Learning within Otganizations". They are looking at how learning occurs; the processes of creating and using knowledge. Others define the phenomenon as a noun or a destination; the "Learning Organization" or the "Learning Company". These researchers describe characteristics of organizations that learn. The belief in a process or a destination has implications for the vision of organizational learning one is trying to establish to guide the efforts of the organization and will be discussed further in chapter three. Theorists offer varying perspectives on three additional dimensions including: the levels within an organization in which learning occurs (individual, group or the organization itself), the definition of learning (beyond the perspective of learning established in the introductory chapter), and the essential structures, competencies and/or practices for the learning organization. The discussion of the OL literature is framed in this chapter using the three dimensions. The literature is presented as it relates to theorist's views of $\mathrm{OL}$ within each dimension and how educators can benefit from an understanding of the different views on knowledge and learning.

\section{Levels of Learning}

Organizational learning theorists discuss and debate the levels at which learning takes place and on the level of learning that is most meaningful to study. Some believe 
that leaming happens on three levels: individual, group and organization. A few believe, as most educators would, that the individual is the only entity capable of learning. Others believe that learning occurs on two levels, individual and group.

Dogson (1993) articulates the belief that individual level learning is the most meaningful: "Individuals are the primary learning entity in firms and its individuals which create organizational forms that enable learning in ways which facilitate organizational transformations." (p.377)

Other researchers argue that the two additional entities within the organization: groups and the organization itself, influence learning and make it difficult, if not impossible, for individuals to have purely new thoughts and act on them without the influence of past organizational learning. The group and organization levels influence individual learning because structures for interpretation, structures for knowledge sharing, and memories exist at these levels. Glynn, Lant and Milliken (1994) state that "newer perspectives on learning focus on the more emergent nature of learning; information to be learned is constructed through the ongoing interactions among organization members" (p. 55).

Nicolini (1995) argues that considering learning only on the individual level is too narrow a focus. His belief is that group and organization level learning are the most important to understand.

Concentrating on individual learning does not explain how an interpreted, communicable, consensual knowledge can be developed.... this reaffirms the importance of taking the organization and its structure as the agent of the 
process.... Only learning embedded in the standard operating procedures, methods of communication and co-ordination and shared understanding about tasks have a persistent effect. ( p. 734)

Seely-Brown (1993) articulates the beliefs of theorists who argue that it is essential to understand learning on the group level as distinct from learning on the individual level.

Learning is a social or community phenomenon. Understanding the process through which groups learn, how they combine individual knowledge and beliefs into shared cognitive structures, and take co-ordinated action is important. Indeed a sense of community, the desire to belong, may be one of the fundamental motivations for learning. (p. 94)

Seely-Brown introduced the concept of "communities of practice" to illustrate the importance of understanding that learning happens in groups. He argues that organizations can benefit from the knowledge and insight created within communities of practice by recognizing they exist and allowing them to thrive. Stewart (1996) makes this observation:

That's an insight with huge - and problematic - implications for managers. Not every group learns. You can't take a dozen people at random, give them a pot of coffee and a box of doughnuts and expect them to learn something. Groups that learn, communities of practice, have special characteristics. They emerge of their 
own accord... They collaborate directly, use one another as sounding boards, teach each other. You can't create communities like this by fiat and they are easy to destroy. ... Communities of practice are the shop floor of human capital... the enterprise involves learning. ( p. 175)

Seely-Brown (1993) tells the story of copier repairers who exchange tips at the water cooler. They learn more through these informal exchanges than in the programmed instruction provided by their organization ( p. 96). People join communities of practice such as this one because they can benefit from and contribute to the learning of the group. Educators should pay attention to the implications that arise from the learning that happens in informal groups. If we can recognize the groups, and diagnose what they learn, we can search for methods and tools to leverage the learning. We may also be able to put people in touch with each other who may be duplicating each other's efforts or who may, together, tackle something that would be too daunting for an individual to achieve. On the other hand, we may be able to uncover and disband groups that learn with destructive outcomes.

The need to recognize the third level of learning as distinct from group or individual level learning is revealed by a number of researchers (Crossan, White and Lane 1993; Simons 1995; Nevis, DiBella and Gould 1995; ECLO 1995; Fiol and Lyles 1985, Nicolini, 1995). Fiol and Lyles (1985) describe the capacity for organization level learning: "Organizations, unlike individuals, develop and maintain learning systems that not only influence their immediate members, but are then transmitted to others by way of 
organization histories and norms.... Organizations do not have brains but they have cognitive systems and memories". (p. 804).

The organization has the ability to preserve attributes such as certain behaviours, mental maps, norms and values over time. Members of the organization share these attributes and use them to understand and interpret their environment. These attributes thus become the foundation for new learning. This is so because "all learning takes place in the context of prior learning" (Driver, 1993, p. 122). A metaphorical "cognitive system" develops at the level of the organization that may be different from the cognitive systems of its individual members and may influence learning more than the individual systems.

Robert-Jan Simons (1995) sums up the beliefs of researchers who believe learning occurs on all three levels:

In studying learning in organizations, one soon discovers that there are three levels of learning: individual learning, group learning and organizational learning.... There is no organizational learning without individual learning and individual learning needs organizational assistance and context to be effective... It is the combination and co-ordination of the three kinds of learning that makes an organization a learning one. (p. 277)

Nevis, DiBella and Gould (1995) go even further and suggest the most meaningful level of analysis is the organization itself: "Learning is a system-level phenomenon because it stays with the organization even if individuals change" (p. 73). The argument 
this trio of researchers presents is difficult to defend because organizations tend to experience a loss of knowledge when key people leave. The organization would never be able to store in its memory all the relevant knowledge held in the minds of individual members.

As illustrated in this brief review of literature, the organization is a social community. Learning takes place in the context of individuals' cognitive schema and also in the context of the beliefs and understanding of co-workers. The organizational culture, embedded rules and norms, strategy and structures are a storehouse of learning at the level of the organization and has great impact on learning at the other levels. Group level learning and organizational level learning are more clearly conceptualized in the discussion of the Learning Matrix and the Learning Assessment Map. For now, it is important to understand that this study is premised on the belief that learning happens on all three levels. The next category to explore is the definition of learning used by OL theorists.

\section{Definition of Learning}

In Education, we commonly conceptualize and define learning in two ways: as a relatively permanent change in behaviour due to experience, or a relatively permanent change in cognition due to experience. (Ormrod, 1995, p.5). The first perspective reflects a collection of theories known as behaviourism. The second perspective reflects a collections of theories known as cognitivism. In corporate education and training, we tend to align with behaviourism and specify learning objectives in terms of desirable, observable behaviours. We use instructional design techniques to teach new behaviours 
and help individuals expand or change their behavioural repertoire. In education, the alignment is mostly likely to be with cognitivism and the goals of developing individual's beliefs, knowledge, attitudes, emotions and values. The cognitive and behavioural perspectives are also discussed in the OL literature and, as in education, there are theorists who tend to align with one or the other perspective.

The OL literature extends the discussion of the perspectives to develop theories to show that both behaviour change and cognitive change are necessary in the definition of learning. A framework that illustrates the outcomes of the complementary processes of cognitive and behaviour change is discussed in this section and will provide insights beneficial for educators. The OL literature contributes additional cognitive theories for conceptualizing learning on two levels: adaptation and transformation. We begin this discussion of the definition of learning with a look at the theory of two levels of cognitive learning developed by Argyris.

Argyris' (1977) large contribution to the field of organizational learning has been his assertion that learning happens on two levels of cognition and results in what he calls "single loop" and "double loop" learning:

One type (of organizational learning) involves the production of matches, or the detection and correction of mismatches, without change in the underlying governing policies or values. This is called single-loop learning. A second type, double-loop learning, does require re-examination and change of the governing values. Single-loop learning is usually related to routine, 
immediate tasks. Double-loop learning is related to the nonroutine, the long-range outcome. (p. 116).

Argyris's work is based'on the premise that individuals and organizations have "frames of reference" or "theories of action" that guide behaviour. Single-loop learning does not require a change in organizational or individual cognitive structures and happens within existing frames of reference. Double- loop learning requires changing the existing frames of reference in order to produce new insights, new knowledge and new action. This latter type of learning can result in organizational transformation. Argyris argues that double-loop learning is very difficult to achieve because people and organizations are not always aware of their theories of action. Even in situations in which people can articulare the need to change underlying structures, the tendency is to maintain alignment between action and existing frames of reference. Another factor Argyris cites which makes double-loop learning difficult to achieve is a defensive reaction: people tend to want to protect themselves by either hiding or covering up mistakes or need for change. Because of this, the need to change is not made public and may not even be considered. Cognitive structures tend to be self-confirming and self-reproducing which makes transformational learning difficult.

Argyris (1977) believes "learning involves a new response or action based on the interpretation... learning is a process of putting cognitive theories to action" ( $p .116$ ) Others who align closely with cognitivism are Foil and Lyles, Driver and Huber.

Fiol and Lyles (1985) define learning as "the development of insights, knowledge, and associations between past actions, the effectiveness of those actions, and future 
actions." (p.809). Driver (1993) defines learning as a cognitive process which he describes as, "any change in long-term memory. These changes can involve laying in engrams for new concepts, skills, beliefs and motives ... they can include large scale cognitive structures.". ( p. 116).

Huber (1991) defines learning and organizational learning in this way: "An entity learns if, through its processing of information, the range of its potential behaviours is changed... an organization learns if any of its units acquires knowledge that it recognizes as potentially useful to the organization" ( p. 89). Huber's definition means that learning can happen without related action being taken. Organizations do not always act on new knowledge; learning has occurred if the new information is deemed to be potentially useful.

In a 1985 article, Fiol and Lyles illustrate the differences in beliefs about learning in the OL literature. Their findings are summarized in Table 2.1. Fiol and Lyles attempted to remove debate in $\mathrm{OL}$ research about defining learning either cognitively or behaviourally by clearly stating that organizational learning must always have a cognitive component. They present the argument that a common use by $\mathrm{OL}$ theorists of the terms "learning", "adaptation" and "change" would move research to a new level.

Fiol and Lyles build on the work of Argyris and assert that learning is always either low-level or high-level cognitive development that may or may not be associated with behaviour development. Learning is defined as "reflective change" which means there is always a cognitive component to learning that results in creation of new causal relationships, new assumptions and changes to the cognitive associations and interpretative schemes among the members of an organization. These changes lead to 
new shared understandings at group levels. Behaviour developments are new responses or actions that are based on the cognitive change. For high level (double-loop) learning to occur, cognitive development redefines the rules and changes the norms, values and mental maps; new knowledge is created and organizational renewal is made feasible. Lower level (single loop) learning does not challenge existing norms, values and rules; only minor modifications of behaviour are made.

Table 2.1 Interpretations of the Term "Learning"

\begin{tabular}{|c|c|c|}
\hline Author & Terms used & Meaning \\
\hline Argyris & $\begin{array}{l}\text { Learning: } \\
\text { Single loop } \\
\text { Double loop } \\
\text { New insights and } \\
\text { knowledge }\end{array}$ & $\begin{array}{l}\text { Low-level cognition } \\
\text { High-level cognition }\end{array}$ \\
\hline Cangelosi and Dill & Learning & Behavioural and cognitive \\
\hline Daft and Weick & $\begin{array}{l}\text { Learning : action after } \\
\text { interpretation }\end{array}$ & Behavioural \\
\hline Hedberg & $\begin{array}{l}\text { Learning: Habit forming } \\
\text { and discovery }\end{array}$ & Behavioural and cognitive \\
\hline Miller and Friesen & Adaptation: new actions & Behavioural \\
\hline Shrivasta and Mitroff & $\begin{array}{l}\text { Learning (systems): } \\
\text { Evolutionary, designed }\end{array}$ & $\begin{array}{l}\text { Behavioural and cognitive } \\
\text { development }\end{array}$ \\
\hline
\end{tabular}

Fiol and Lyles (1985) assert that pure behaviour change is adaptation, not learning. They distinguish adaptation and learning in this way: 


\section{Adaptation}

The ability to make incremental adjustment as a result of environmental changes, structure change, or other change.

\section{Learning .}

The development of insights, knowledge, and associations between past actions, the effectiveness of those actions and future actions. Low level: Focused learning that may be mere repetition of past behaviour - usually short-term, surface, temporary, but with associations being formed. High level: The development of complex rules and associations regarding new actions. Development of an understanding of causation. (p. 811)

The definition of learning employed by a theorist complicates the measurement of learning because cognitive change can happen without ever being reflected in observable behaviour. To the observer, pure behaviour change would look like learning.

The theoretical framework presented in Figure 2.1, developed by Crossan (1991) helps to bring the cognitive and behavioural perspectives together and illustrates the outcomes of varying degrees of cognition and behaviour change. In the framework, cognitive change and behavioural change are arrayed against one another. In the upper left quadrant, there is no cognitive change and no behavioural change, therefore, no learning is taking place. In Integrated Learning, illustrated by the lower right-hand quadrant, change is occurring cognitively and behaviourally. Integrated Learning is the most desirable because it is relatively permanent. The remaining quadrants reflect varying degrees of cognitive and behavioural change. 
Figure 2.1 Cognition and Behaviour Change

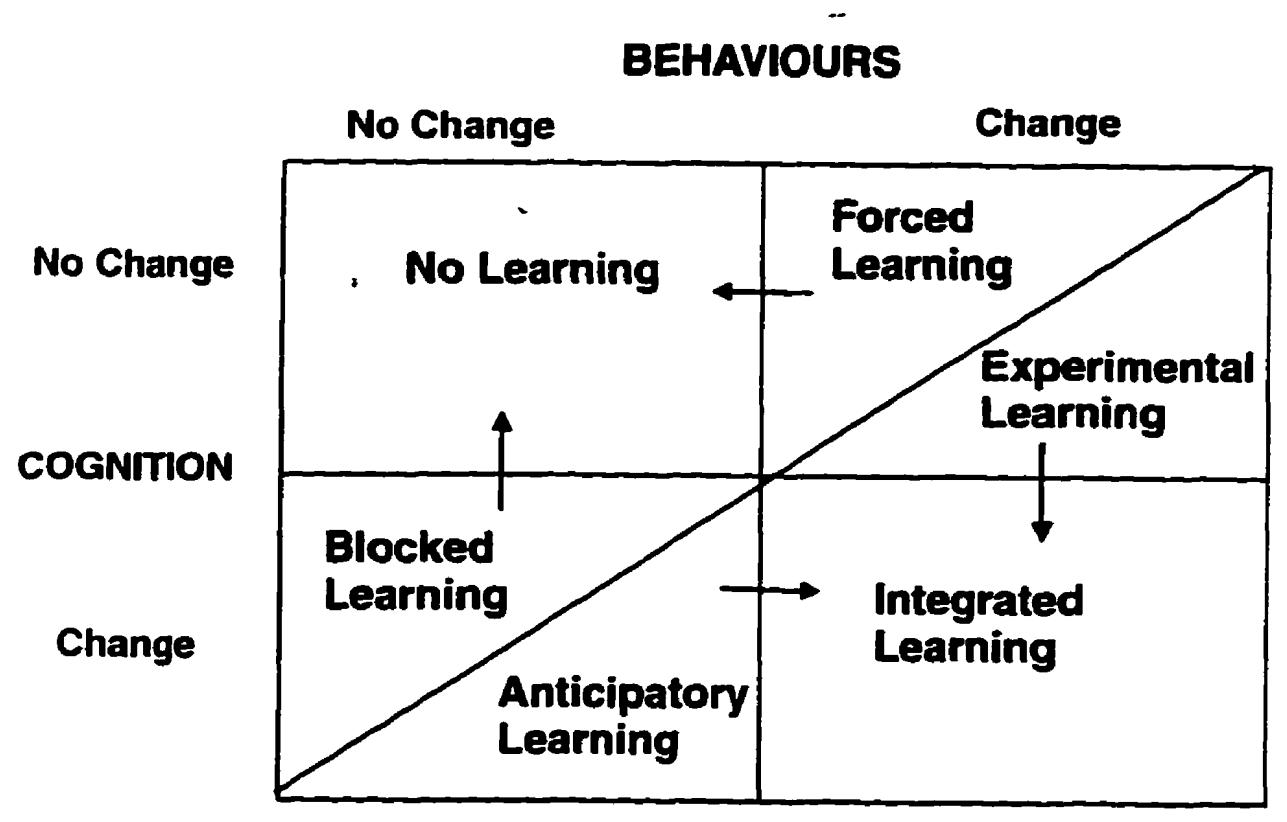

Forced Learning, as illustrated in the top section of the upper right-hand quadrant, is behaviour change without cognitive change. Training and incentives may influence this type of learning but the person engaged in the learning may not really understand or believe in the change. The person or organizational unit that has been forced to change does not change its own frame of reference to align with the new behaviour. Behaviour may revert to a previous state when incentives are removed so that the person's behaviour is in agreement with beliefs. At a point in time, Forced Learning may be interpreted as relatively permanent learning because it involves an observable behaviour change.

Experimental Learning is illustrated in the bottom section of the upper right-hand quadrant of the matrix in Figure 2-1. A person in this section of the quadrant suspends his or her belief to try a new behaviour. If the person has a positive experience with the 
new behaviour, Experimental Learning may resolve into Integrated Learning where both cognition and behaviour change. However, similar to Forced Learning, a behaviour change may or may not lead to change in cognitive associations. The new behaviour may be dropped without any underlying cognitive change - in such instances, Argyris and Foil and Lyles would argue that learning has not occurred.

Blocked Learning involves cognitive changes that do not lead to behaviour changes. Some conditions exist in the organization that do not allow the behaviour change. Blocked Learning is not observable and may not be conscious for the learner. To measure cognitive change, one must rely on statements of people in order to determine if this type of learning is occurring and being blocked from resulting in new behaviour.

A person or organizational unit involved in Anticipatory Learning, illustrated in the lower left-hand quadrant of Figure 2-1, has changed cognitively and that may result in a change in behaviour or actions and therefore resolve itself into Integrated Learning. The entity has internalized knowledge that it recognizes as potentially useful to the organization but has not yet acted on it.

The definition that is most meaningful to me as a practitioner is the definition of Integrated Learning; learning that involves cognitive and behavioural change. For learning to be sustainable, it needs to have a balance of both components of learning.

In training, we struggle with the problem of sustaining behaviour change over a long time. We administer training and can initially observe behaviour changes in individuals. Often however, the behaviour change is not sustained. The reasons for this are partially environmental - a manager or the work environment does not support the 
behaviour change. Another reason for the lack of sustained behaviour change could be that we tend not to teach the theoretical or factual reasons for change. We are typically not concerned with developing learners cognitively, we tend to focus efforts on behaviour change. In education, the learning is more anticipatory. Students learn and have new knowledge, but are not always immediately able to apply the knowledge to new actions. Detailed knowledge learned in school can be lost overtime because it is not put into action.

The value of understanding the behaviour/cognition framework is knowing that different types of learning can take place and that we need to have a practical knowledge of behaviourism and cognitivism. In our vision for a learning organization, we can think about what types of learning are required to achieve certain goals. Ultimately, we will strive predominately for Integrated Learning but there may be times when it is desirable to use Forced Learning or Anticipatory Learning and structure the environment or learning events to achieve this type of learning. To achieve Integrated Learning we need to develop abilities to know how to design learning environments and events that can change people and groups both behaviourally and cognitively.

\section{Essential Processes, Competencies and Practices}

Similar to the preceding discussion of cognitive and behavioural change in learning, some researchers cite a cognitive concept - information processing - as the mechanism for OL (Huber 1991, Dixon 1992, Daft and Weick 1984, Sinkula, 1994, Simons 1995) while others take a behavioural approach citing various skills, knowledge 
and behaviour as essential for OL (Senge 1990, Arygris 1977, Garvin 1993, Nevis 1995). Review of literature in this category begins with a presentation of the frameworks for information processing.

\section{Processes}

Huber (1991) proposes a comprehensive framework of organizational learning processes that incorporates the work of a number of theorists. Huber's framework includes four constructs and related subconstructs and subprocesses. The framework is shown in Table 2.2 .

From the body of work he examined, Huber extracted four principal constructs for organizational learning: knowledge acquisition, information distribution, information interpretation and organizational memory.

Huber uses the terms knowledge and information interchangeably and gives this explanation for doing so:

I have tried to use information when referring to data that give meaning by reducing ambiguity, equivocality, or uncertainty, or when referring to data which indicate that conditions are not pre-supposed, and have tried to use knowledge when referring to the more complex products of knowledge, such as interpretation of information, beliefs about cause-effect relationships or, more generally, "know how". (p. 89) 


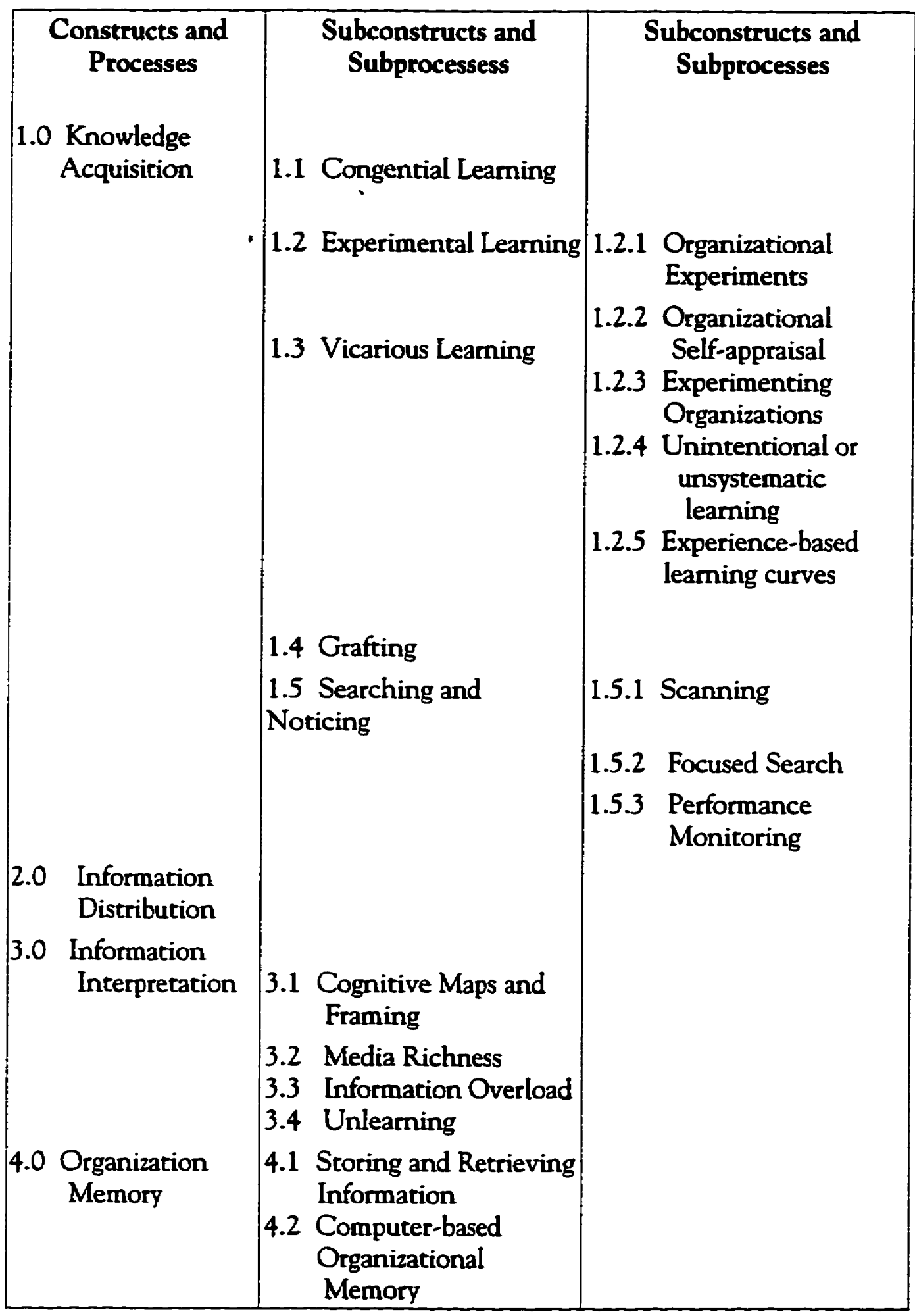

Table 2.2 Huber's Constructs and Processes of Organizational Learning 
The first step of Huber's framework, Knowledge acquisition has five related processes and subprocesses: drawing on knowledge available at and before the organization's birth; learning from experience; learning by observing other organizations; grafting on components that possess knowledge not already possessed by the organization (through arrangements such as mergers, acquisitions, partnerships); and intentional searching for information about the environment and performance of the organization within the environment. Learning from experience is broken down into five additional subprocesses that include intentional and unintentional efforts to acquire knowledge. It is through all of these processes that the organization acquires knowledge that is potentially useful. Thinking of learning as a linear process, knowledge acquisition is the starting point.

All OL process frameworks include a step of knowledge acquisition. It is generally agreed that organizations need to manage the procedure for acquiring information both externally and internally. Theorists caution about a number of issues that impact how information is gathered. Some organizations do not engage in many external information acquisition efforts for fear of appearing vulnerable. Powerful filters for information exist in organizations that may block certain information from getting through to the organization and may block the process of the right information getting to the people who are most likely to learn from the information. The information filters may be deliberate attempts to block information or the filters may be unintentional. An additional weakness in knowledge acquisition is that groups within the organization who gather relevant information for learning may not be aware of other groups who can 
benefit from the information. The flow of information might therefore be blocked by ignorance or misunderstanding of another unit's information needs. Argyris believes that powerful filters and blocks of information exist intentionally because people tend to want to protect themselves by either hiding or covering up information that reveals a mistake or a need to change. Admitting failure or being wrong is difficult for people so they will block the knowledge acquisition process to protect their reputation.

At the next level, information distribution, information is disseminated to those in the organization who need it. The process of information distribution has a large impact on learning because the occurrence and breadth of learning is dependent on this process. Information has to get to the right people and the right number of people in a timely manner and not be unreasonably distorted along the way. For learning to be broadly-based, information must get to a variety of places in the organization.

The next step in a linear learning process is information interpretation. It is at this step that information is given meaning and the resulting action (which could include no action) is decided. The process of interpretation is critical for learning. Some OL theorists work only in this construct and define organizational learning as an interpretative process. Daft and Weick (1984) define learning as "the process through which information is given meaning and actions are chosen" ( p. 285). A decision to take a new response or action is based on how the information is given meaning and to what extent the interpreted meaning is shared amongst those to must act on the information. Huber (1991) describes the effect on learning of the four subconstructs of Information Interpretation: 
The extent of shared interpretation of new information is affected by (1) the uniformity of prior cognitive maps possessed by the organizational units, (2) the uniformity of the framing of the information as it is communicated, (3) the richness of the media used to convey the information, (4) the information load on the interpreting units, and (5) the amount of unlearning that might be necessary before a new interpretation could be generated. ( p. 102).

For goal- directed learning to occur, information needs to be translated and a degree of shared understanding developed. Groups and individuals may come to a shared understanding very quickly or may have difficulty ever achieving shared understanding. Theorists struggle with determining the desirability of quickly achieving shared understanding as opposed to groups debating a variety of interpretations. If shared understanding is accomplished too quickly it may be at the expense of considering valid and relevant diverse interpretations that may result in more effective action being taken. People should be aware that in order to help the interpretation process, information should be framed in a specific, widely understood context when it is distributed so that achieving uniform interpretations is facilitated.

Organizational memory, the final construct in Huber's framework, is stored information and organizational artifacts. Organizational memory influences learning in four primary ways: 
1. To demonstrate or use leaming, that which has been learned must be stored in memory and then brought forth from memory; both the demonstrability and usability of learning depend on the effectiveness of the organization's memory,

2. Information acquisition depends in many instances on attention, which is directed by previous learning retained in memory,

3. Information distribution is affected by organizational decisions made using information contained in memory,

4. Information interpretation is greatly affected by cognitive maps or frames of reference, which are undefinable except in terms of memory. (Huber, 1991, p. 106)

Information is stored in many places: the human brain, manuals, paper files, and computer files. Accurate recording of information, accurate and complete recall of information, and interpretation of the information at the time of storage all impact learning. The strength of organizational memory is dependent on a number of factors:

Everyday observations make clear (1) that personnel turnover creates great loss for the human component of an organization's memory; (2) that nonanticipation of future needs for certain information causes great amounts of information not to be stored.. (3) that organizational members with information needs frequently do not know of the existence or whereabouts of information possessed or stored by other members. In 
addition, humans are deficient as repositories of organizational information and knowledge . (Huber, 1991, p. 105)

Huber's framework provides a good orientation to the relevant processes of organizational learning. The fundamental steps he presents can be seen in the frameworks of other theorists who take an information processing view of organizational learning (Dixon 1992, Daft and Weick 1984, Simons 1995, Sinkula 1994). Dixon's (1992) learning cycle for organizations uses much of the same terminology and resembles Huber's.

Table 2.3 Dixon's Process of Organizational Learning
1. Acquisition of knowledge
2. Sharing of knowledge
3. Constructing meaning
4. Organizational Memory
5. Retrieval of Information

Daft and Weick (1984) define the overall learning process as a three step process and is shown in Table 2.4. Daft and Weick do not emphasize the construct of organizational memory. Most of their work is in the area of interpretation. They believe that an organization's capacity for learning is dependent on how it searches for information about its environment and how information is interpreted.

Table 2.4 Daft and Weick's Process of Organizational Learning 1. Scanning: Data Collection

2. Interpretation: Data Given Meaning

3. Learning: Action Taken 
Nevis, DiBella and Gould (1995) identify a three step information processing cycle and support it with seven learning orientations and ten facilitating factors to help develop learning abilities. The three stages of the cycle are listed in Table 2.5.

Table 2.5 Nevis, DiBella and Gould's Cycle of Organizational Learning

1. Knowledge Acquisition: the development of skills, insights, relationships.

2. Knowledge Sharing: the dissemination of what's been learned

3. Knowledge Utilization: the integration of learning so it is broadly available and can be generalized to new situations.

The facilitating factors that Nevis, DiBella and Gould identify as essential introduce behavioural processes that affect the ease at which learning occurs and the amount of effective learning that takes place. The facilitating factors are listed in Table 2.6. The learning orientations, listed in Table 2.7 , are described as the values and practices within the organization that reflect where learning occurs and the nature of what is learned.

Table 2.6: The Ten Facilitating Factors That Expedite Learning 1. Information gathering practices in the internal and external environment

2. Awareness of performance gaps to motivate learning

3. Effort spent on measuring key factors that determine needs for and outcomes of learning

4. Support for experimentation

5. Climate of openness

6. Continuous Education

7. Variety of methods, procedures and systems that allows adaptation

8. Multiple advocates at all levels to advance new ideas

9. Involved leadership

10. Interdependence of organizational units which leads to widespread accountability 
Table 2.7: Learning Orientations for the Learning Organization

Knowledge Source: Internal vs. External. The organization's preference for
developing knowledge internally or externally.
Product - Process. Focus: The emphasis on accumulation of knowledge about
products and services verses how the organization develops, makes and delivers its
products and services. Is the organization organized to learn about both?
Documentation Mode: Formal - Informal: Is knowledge something the individual
has or is knowledge publicly documented and shared?
Dissemination Mode: Formal - Informal: Formal, prescribed organization-wide
methods of sharing learning vs. informal methods such as role-modelling and
casual daily interaction.
Learning Focus: Incremental - Transformational: Is learning concentrated on
methods and tools to improve what is already in place or on testing the
assumptions underlying what is being done? A sound learning system benefits from
work in both areas.
Value-Chain Focus: Design- Deliver: Emphasis on learning investment in
engineering/production activities verses sales and service activities.
Skill Development Focus: Individual - Group: Development of the individual's
skills verses team skills. An organization should be able to assess how it is doing in
both of these skills areas and improve one or both. (p. 77 )

Knowledge Source: Internal vs. External. The organization's preference for developing knowledge internally or externally.

Product - Process. Focus: The emphasis on accumulation of knowledge about products and services verses how the organization develops, makes and delivers its products and services. Is the organization organized to learn about both?

Documentation Mode: Formal - Informal: Is knowledge something the individual has or is knowledge publicly documented and shared?

Dissemination Mode: Formal - Informal: Formal, prescribed organization-wide methods of sharing learning vs. informal methods such as role-modelling and casual daily interaction.

Learning Focus: Incremental - Transformational: Is learning concentrated on methods and tools to improve what is already in place or on testing the assumptions underlying what is being done? A sound learning system benefits from work in both areas.

Value-Chain Focus: Design-Deliver: Emphasis on learning investment in engineering/production activities verses sales and service activities.

Skill Development Focus: Individual - Group: Development of the individual's skills verses team skills. An organization should be able to assess how it is doing in both of these skills areas and improve one or both. (p. 77 )

The analysis of the literature relative to essential structures and processes reveals that researchers are working within all constructs and various dimensions of the broad framework presented by Huber. Some of the items on the Learning Assessment Map capture perceptions of how well the processes described by Huber support learning in 
organizations and if facilitating factors similar to those described by Nevis, DiBella and Gould are in place.

\section{Behaviours}

Huber's framework does not pay much attention to learning behaviours and skills. The Nevis, DiBella and Gould framework incorporates behaviours but does not rely on them as much as the frameworks that will be presented next. A discussion of the work of theorists who take a competencies-based approach to the study of organizational learning begins with a presentation of the work of Senge.

In the introductory chapter, Senge's (1990) definition of organizational learning was presented:

Learning Organizations are organizations where people continually expand their capacity to create the results they truly desire, where new and expansive patterns of thinking are nurtured, where collective aspirations are set free and where people are continually learning how to learn together. (p.3)

Senge's contributions have been important to the practitioner. Senge's theoretical framework for building a learning organization involves five essential learning disciplines for organizations and a framework of three stages necessary for application of the disciplines. 
Table 2.8 Senge's Five Learning Disciplines

Personal Mastery - Individual commitment to develop one's own capacity for learning. Each person must continually clarify and deepen their own personal vision.

Shared Vision - The organization must be able to continually build commitment to goals. The thinking and action of each person must be aligned with these goals. A sense of common purpose must prevail in the organization.

Mental Models - People must be aware of their mental models and able to articulate the unspoken assumptions and norms that shape their actions and decisions. Revealing mental models enables individuals to achieve breakthroughs by surfacing and testing assumptions.

Team Learning - Organizations must posses collective thinking skills so groups can develop intelligence and ability greater than individuals. Employees must be able to learn in teams and as teams.

Systems Thinking - Systems thinking is the ability to discover structural causes of behaviour and see interrelationships rather than only linear cause and effect. This competency links the other four. Within a system, individuals must understand the underlying structures well enough to find leverage points for change and know what to do to change. ( p. 42)

Senge presents a three stage framework that is required for transformational learning to occur. He argues that organizational learning is a continuous cycle of change that happens in three stages. The stages include both cognitive and behavioural change on the levels of individuals and groups. The three stages are illustrated in figure 2.2 .

The deep learning cycle represents underlying cognitive changes that are not observable. 
This deep learning cycle constitutes the essence of the learning organization - the development not just of new capabilities, but of fundamental shifts of mind, individually and collectively. The five basic learning disciplines are the means by which this deep learning cycle in activated. Sustained commitment to the disciplines keeps the cycle going. (Senge, 1994, p.18)

\section{Figure 2.2: Senge's Continuous Cycle of Change}

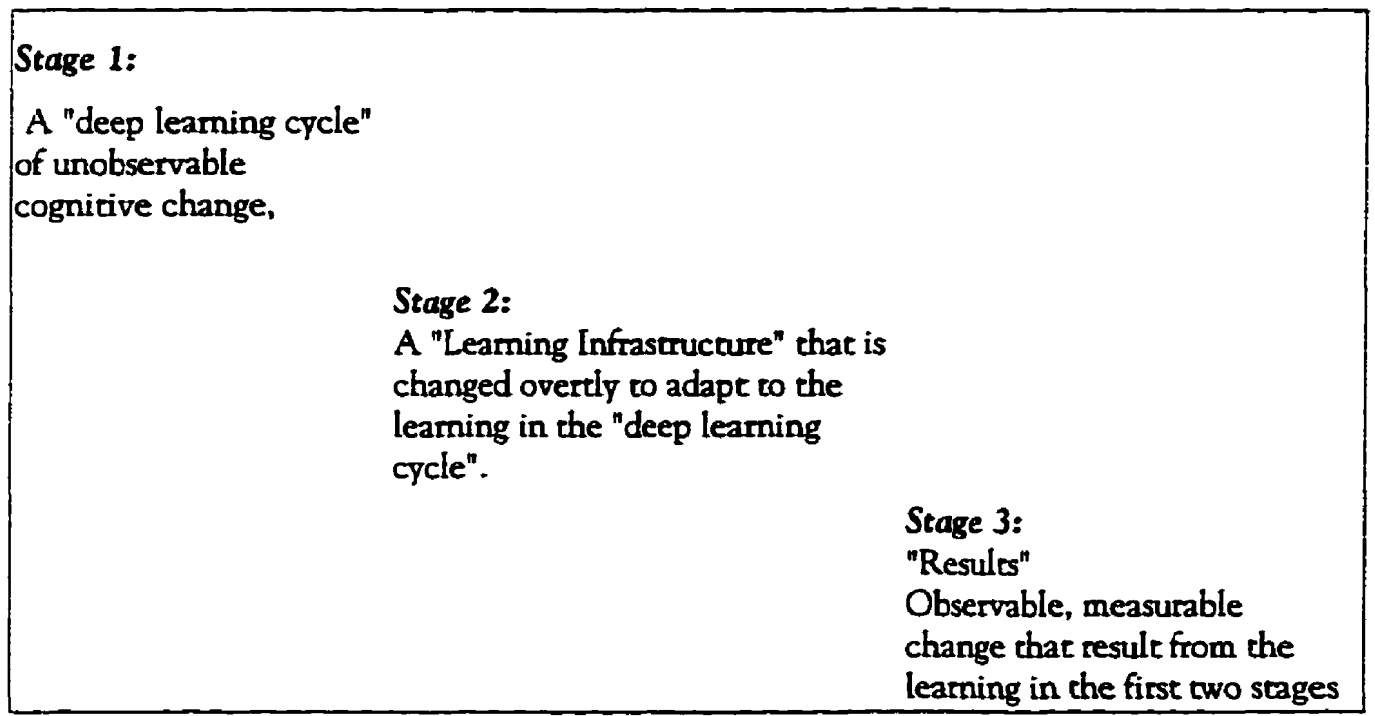

There are three elements related to the deep learning cycle: awareness and sensibilities; attitudes and beliefs; and skills and abilities. The skills and abilities are:

1. Aspiration to change: The capacity of individuals and teams to orient themselves toward what they care about and to change because they want to. 
2. Reflection and conversation: The capacity to reflect on deep assumptions and patterns of behaviour, both individually and collectively. The ability to have "learningful" conversations.

3. Conceptualization: The capacity to see larger systems and forces at play and to construct public, testable ways of expressing these views. (Senge, 1994, p.19)

A fundamental change in any one of the elements in the deep learning cycle will lead to changes in the other elements in the cycle. Changes in the deep learning cycle may lead to the visible changes of any of three elements related to the learning infrastructure: guiding ideas (shared understanding of what the organization exists for and where it is going); theories, methods and tools; systems that guide the behaviour of individuals and groups within the organization.

A learning organization must foster development of the capabilities of aspiration, reflection and conversation, and conceptualization by becoming engaged in the five learning disciplines. The organization must have the ability to continually turn the learning in the deep learning cycle into new shared understandings, construct new systems and/or look for tools based on important new theories in order to evolve the way people think and act. Senge contends that "builders of learning organizations must develop and improve infrastructure mechanisms so the people have the resources they need: time, management support, money, information, ready contact with colleagues, and more." (Senge, 1994, p. 32)

Senge's premise that structure leads to certain behaviours includes systemic structure of an organization (culture, policies, procedures, organizational hierarchies) and 
individual and collective mental models. Fixing problems by trying to fix behaviour (Forced Learning) will only mask underlying problems for a short time. Systems thinking means that people understand the underlying structures and what changes to them are needed to solve problems and impact results. Senge's remarks help to substantiate the argument presented by the cognition/behaviour matrix in figure 2.1. A balance of cognitive and behavioural change is required for relatively permanent learning to occur.

Similar to Argyris, Senge believes that it is the organization's capacity for double-loop learning that makes it a true learning organization. Senge uses the term "generative" learning for double-loop learning, and contrasts it to "adaptive" learning which is equivalent to Argyris' definition of single-loop learning. Also in agreement with Argyris, Senge asserts that frames of reference must be analyzed and changed if necessary in order to achieve generative learning.

The deep learning cycle in Senge's framework is the institutional or organizational memory as it is described by others. Senge acknowledges that changing the deep learning cycle is difficult and can take years. Institutionalized memory can be a bartier to generative learning. Senge's main premise however is that a true commitment to practising the five learning disciplines can overcome barriers imposed by institutionalized memory.

For educators, Senge's work reveals that our greatest point of leverage to affect OL is most likely at stage 2; developing and improving infrastructure. Work at this stage can involve: facilitating buy-in to organizational mission and goals; developing theories, methods and tools for changing individuals and groups cognitively and behaviourally; and 
facilitating the continuous refinements of the five leaming disciplines facilitating the storage and retrieval of information.

Garvin (1993) builds on Senge's theories and offers some practical tools and techniques educators,can use to develop and improve the learning infrastructure. Garvin describes five building blocks each requiring a distinctive mind-set, tools and patterns of behaviour. The five building blocks are described in Table 2.9.

\section{Table 2.9 Garvin's Five Building Blocks for Learning Organizations}

Systemic Problem Solving: A consistent process for problem solving must involve tools and methods for collecting facts and data, systematically analyzing each with an open mind, identifying causes of behaviour and deciding on action to take.

Experimentation with new approaches: Programs to find out about innovative approaches and experiment (sabbaticals to other companies, encouragement of risk taking).

Learning from experience and history: Activities to reflect on the past, review success and failures and record learning in a format that is open and accessible.

Learning from the best practices of others: Processes for ongoing benchmarking activities that ensure the best industry practices are uncovered, analyzed, adopted and implemented.

Transferring knowledge quickly and efficiently: A common vocabulary is required to minimize time and effort spent on interpretation. Activities to achieve this competency include personnel rotation, education and training, centrally produced communications, and standardization programs.(p. 79)

Garvin stresses that programs need to be in place to acquire information internally and externally, analyze and interpret the information, think about strategic plans, assess current work, find out what other companies are doing, and stimulate exchange of ideas. The organizational climate needs to be receptive to new ideas and allow time for reflection and analysis. Staff must be open to criticism and willing to experiment and 
self-reflect. The organization climate must be tolerant of mistakes made in an effort to push the organization forward and be open to allowing time for experimentation with new ideas.

A number of theorists write specifically about the influence of organizational climate (or culture) on learning (Foil and Lyles 1985, Simons 1995, Sollman 1995, Campbell 1985). Simons (1995) makes two observations about culture: culture can make a positive contribution to learning in that it prevents the organization from making the same mistakes over and over again; culture can also have a negative influence on learning in that it can be a powerful hurdle to change and learning. Sollman (1995) also identifies climate as an important organization element for learning.

If the organizational climate is learning unfriendly, individuals will perceive low probability of engagement in learning activities yielding desirable outcomes, such as financial rewards, social recognition or self achievement. They may even expect that engagement in learning will lead to negative outcomes, such as social isolation. An important part of the learning climate is the organization's reactions to errors. .. There is some evidence that the values and norms of an organization's corporate culture, reflected in prevailing management style as well as in its policies and systems, considerably influence the organization's learning processes. (p. 424).

A review of Sollman's (1995) dimensions of general organizational climate and Campbell's (1995) dimensions of corporate culture have lead to the following list of five dimensions of corporate culture which stress cultural values and organizational systems. 
1. Communication and Co-operation - A learning-friendly organizational culture is characterised by open and free communication, trust and mutual support. Information flows horizontally, upwards, downwards and across functional areas. 2. Learning From Error - The culture's tolerance for experimentation and viewing failures as learning opportunities will impact learning. Companies that tolerate errors will be better able to detect errors, prevent and reduce error rates. 3. Reward and Recognition - An organizational reward system which favours innovative and creative behaviour promotes learning.

4. Innovation - Prevailing attitudes toward innovation are an important dimension of the culture to measure. Does the culture value diverse perspectives, experiences, risk taking and experimentation or is the emphasis put on conformity with existing rules, beliefs and norms?

5. Decision Making - The degree of autonomy of decision making and participation in important organizational decisions. Are employees responsible for the decisions they make? Employees are more likely to learn from their mistakes if they feel responsible for their actions and are involved in important decisions. 6. Ability to "unlearn" - Hedberg (1981) defines "unlearning" as making room for new ideas and cognitive frameworks in order to foster new knowledge. Unlearning is very difficult if not impossible because people cannot easily abandon old ways of thinking and adopt new ones. Otganizations cannot easily forget their history and discard old values and norms. To operationalize the concept of unlearning, it is important to consider if people are able to articulate underlying 
assumptions, set counterproductive ways of thinking aside, and allow new ways of thinking to influence action.

\section{Structure}

Structure is an important organizational level construct to consider and has not been specifically addressed in the literature review so far. It is important because: "though most authors believe structure is an outcome of $\mathrm{OL}$, it usually conditions OL itself." (Nicolini and Meznar, 1995, p. 731). The perceived affect of structure on learning is measured by the Learning Assessment Map so it is important to review some of the key arguments about structure. Disagreements exist amongst researchers regarding optimal organizational structure for learning. Some argue, as Foil and Lyles (1985) do, that the most influential aspect of structure is the amount of centralized versus decentralized decision-making; " Centralized and decentralized decision-making structures have very different impacts on the organization's learning ability. Centralized structures tend to reinforce past behaviour (slowing learning) while decentralized structures facilitate the assimilation of new patterns and associations. (p. 805)

Not all researchers agree with Fiol and Lyles and argue that, for some organizations, a centralized decision-making structure does not hinder learning. Nicolini and Meznar (1995) summarizes the opinions of a number of researchers:

The recognition that certain structures are more conducive to OL than others has led some authors to support the argument that organizations should be intentionally designed as to enhance their capability to learn. ... 
Duncan and Weiss (1979) apply a contingent approach and argue that finding the optimal organization design results from learning which is the appropriate structure to face the perceived environment. Daft and Huber (1987) argue that the proper structure to promote learning depends on the amount of information the organization needs to process and the equivocality of that information. ( p. 731)

Gephart et al. (1995) contend that there are three elements to structure that influence learning: organizational roles and relationships should be structured flexibly; work structures should enable those closest to the problem to solve it and structures should allow learning to be captured and shared. For example, structure can restrict the development of communities of practice or allow them to thrive.

This chapter has provided a descriptive overview of the literature from the field of OL. As presented in the chapter, in each of the three dimensions discussed: levels of learning; definition of $\mathrm{OL}$; and processes and behaviours for $\mathrm{OL}$, there is some convergence in thinking amongst theorists and some issues that continue to be debated. The Learning Matrix provides a means to begin to pull together the viewpoints in each dimension and consolidate our understanding of OL. The Learning Matrix is discussed in the next chapter. 


\section{Chapter Three: Theoretical Framework}

The Learning Matrix is a culmination of $\mathrm{OL}$ research done at the Richard Ivey School of Business at the University of Western Ontario. The group of researchers who created the Learning Matrix provide this definition of OL: " the process of change in individual and shared thought and action, which is affected by, and embedded in the institutions of the organization." (Crossan and Hulland, 1996, p.2). The definition focuses on organizational learning rather than defining a learning organization as in the

definitions offered by Garvin (1993), Fiol and Lyles (1985) and Pedler, Burgoyne, Boydell (1991) presented in chapter two. The framework captures the dimensions of OL described in the literature review. The assumptions on which the framework is built are summarized in Table 3.1.

The Learning Matrix captures the "soft" aspects of OL such as Senge's five disciplines (personal mastery, shared vision, mental models, team learning and systems thinking) and the "hard" processes described by Huber (knowledge acquisition, information distribution, information interpretation and organizational memory).

\section{Levels of Learning}

The Learning Matrix is based on the premise that organizational learning happens at three levels; individual, group and organization. Otganizational learning is more complex than the sum of learning at the level of individual members. Crossan et al. assert that although $O L$ theorists have placed different emphases on the individual, group 
and organizational levels of learning, a comprehensive framework needs to consider all three $(1995$, p.3).

Table 3.1 Assumptions Underlying the Learning Matrix

\begin{tabular}{|c|c|}
\hline Levels of Learning & $\begin{array}{l}\text { Learning happens at three levels (individual, group and } \\
\text { organization) and complicating tensions exist amongst } \\
\text { these levels. }\end{array}$ \\
\hline $\begin{array}{l}\text { Definition of } \\
\text { learning }\end{array}$ & $\begin{array}{l}\text { Learning involves changes in cognition and behaviour. } \\
\text { Learning and performance are not necessarily directly } \\
\text { and positively related. }\end{array}$ \\
\hline $\begin{array}{l}\text { Essential } \\
\text { structures, } \\
\text { processes and } \\
\text { behaviours. }\end{array}$ & $\begin{array}{l}\text { There is not an ideal learning organization. The structures, } \\
\text { systems and practices must be managed to ensure they are } \\
\text { appropriate for the particular organization. There are } \\
\text { distinct learning processes that occur at the three levels of } \\
\text { learning: intuiting, interpreting, integrating and } \\
\text { institutionalizing. }\end{array}$ \\
\hline
\end{tabular}

The Learning Matrix defines two categories of group learning: the learning that arises from formal and informal work groups and the learning that is associated with leadership. The Learning Matrix recognizes leaders and managers as an isolated group that has a particularly strong influence on organizational learning. 
The Learning Matrix defines the organization level as the systems, structure, procedures, strategy, culture and other non-human organizational artifacts that are storehouses of learning. The organizational level embeds learning that flows from individual and group learning systems and procedures.

\section{Definition of Learning}

An underlying assumption of the Learning Matrix is that organizational learning is a process of change in both cognition and behaviour and acknowledges the notion that learning and performance are not directly and positively related. The creators of the framework concur with Huber's observation:

Learning does not always increase the learner's effectiveness... entities can incorrectly learn, and they can correctly learn that which is incorrect... learning need not result in observable changes in behaviour.... learning may result in new and significant insights and awareness that dictate no behavioural change. (Huber, p. 89)

Extending Huber's argument, learning can also result in incorrect behaviour changes which do not improve performance and may negatively affect performance. For the practitioner trying to influence performance improvement in organizations, it is important to understand the learning processes that exist and the co-relation between learning behaviours and performance. 


\section{Learning Processes}

The Learning Matrix is premised on the theory that there are four meta-processes for learning at the individual, group and organization levels. The four meta-processes are "intuiting" and "intetpreting" at the individual level; "integrating" at the group level; and "institutionalizing" at the organization level. The four processes can most easily be conceptualized when described in a linear process. I have adapted an example of a start-up organization used by Crossan and Tiemessen (1995) to describe each type of learning . Consider the example of an entrepreneur with an idea to start a private school.

\section{Intuiting}

The entrepreneur has a vision of what the school will be, who will attend and what a day at school will be like for students. His ideas are based on experiences. He has vivid mental images of what this organization could be and develops metaphors to share his ideas with others.

\section{Interpreting}

The entrepreneur must interpret information about the environment in which the school will exist. Recognizing that he can not start and run a school on his own, the entrepreneur hires people to help him. The start-up ideas are interpreted by others through dialogue. Some structure begins to be put around the ideas. Individuals working with the entrepreneur begin to form conceptual maps of processes and structures for achieving the vision for the private school. A language starts to form that is unique to the organization. 


\section{Integrating}

Through shared understandings, the conceptual maps of the individuals become integrated. Teachers and resource people are hired and groups or departments are formed. Each of these groups has a vision and goals. As the groups begin to talk about what role they will play in this school and how to achieve their desired outcomes, they adjust their own ideas and actions to make their actions complement and build on the actions of others. Up to this point in the development of the school, the interactions may have been largely informal. Now more formal processes start to be worked out.

\section{Institutionalizing}

Through the formalization of processes and structures, the organizational storehouse of systems, procedures, formalized rules and routines, etc. are built. The groups have decided what subjects will be taught, how to teach them, how students will be grouped into learning units, if and how students will move from one place to another, when the school day begins and ends, how students will be evaluated, in what way parents will be involved, and the salaries of teachers.

The school has formalized structures and procedures that achieve the vision of the entrepreneur. People working in and attending the school know their roles. Meetings with people now must be arranged in advance whereas meetings may have been informal and spontaneous at other stages of learning. Meeting agendas now guide discussions. There is a structure in place that includes plans, procedures, rules and understanding amongst individuals and groups about how to operate on a daily basis. 
Norms and values for the school have developed. Decision making by people working in the school is less spontaneous than at earlier stages. The school becomes less responsive to change and new ideas than it had been as an informal structure. Individual and group learning becomes institutionalized. The process of institutionalization embeds past learning into the organization. An organizational culture starts to emerge and strengthen.

New ideas brought into the organization by a new member or that come from existing members will be interpreted in the context of the outcomes of instituionalized learning. The belief that "all learning takes place in the context of prior learning" (Driver, 1993, p.122) means that new ideas could result in only "single loop" learning because they are likely to be interpreted in the context of existing rules and norms. On the other hand, with well developed learning skills, the institutionalized knowledge can be a catalyst for "double-loop" learning.

The ongoing use of the four types of learning is desirable in the organization but now more difficult to isolate and manage. Although the organization is functioning effectively, now information and environmental change will require the development of new structures and behaviours. To generate these new outcomes, the organization needs to manage its ongoing ability to foster intuition that results in new ideas, new interpretations that may require change in collective thinking, integration of the new ideas, and institutionalization of new processes, practices and behaviours into the system.

Each of the discrete learning processes can potentially result in the refinements of important learning abilities as outlined in Table 3.2. 
Table 3.2 Potential Outcomes of Learning

\begin{tabular}{|l|l|l|}
\hline Individual & $\begin{array}{l}\text { intuiting and } \\
\text { interpretation }\end{array}$ & Increase in human capital and capability. \\
\hline Group & integration & Modification or wide-scale change in \\
& shared understanding and shared cognitive \\
\hline Organization & institutionalization & structures resulting in co-ordinated action. \\
\hline & Changes to all or some of the non-human \\
& context for learning: systems, structure, \\
strategy, procedures, norms of behaviour \\
and culture.
\end{tabular}

The Learning Assessment Map reveals people's perceptions about the patterns of learning in the organization. Responses to items on the instrument gives an indication of the extent to which people believe the discrete learning processes are in place and how the types of learning impact each other.

\section{Essential Structures, Processes and Practices}

The Learning Matrix is premised on the belief that there is no ideal pattern of learning for an organization in order to effectively and appropriately engage in both "single loop" and "double loop" learning. 
Otganizations will have different patterns of learning for different work units, functional areas, or levels of the organization... the patterns need to be assessed relative to the associated tasks. Ultimately, organizations will have different patterns of learning depending upon the industry in which they operate, their competitive position in the industry, and their stage of development. Rather than defining one type of learning organization, it will be critical for researchers and managers to begin to diagnose the patterns of learning in organizations to assess whether the patterns facilitate or inhibit taking action given the organizational context. (Crossan et al, 1995, p. 25)

\section{The Learning Matrix}

The Learning Matrix is a nine cell structure in which the three levels of learning are put on both the vertical and horizontal axis. The matrix is shown in figure 3.1. On the vertical axis, the levels of learning represent causes or inputs to learning and on the horizontal axis, the levels represent results or outcomes. For example, the top middle cell, I-G, represents individual level learning resulting in group level learning. The diagonal represents the process of moving through the discrete learning processes: intuiting, interpreting (I-I), integrating (G-G) and institutionalizing (O-O). All the cells within the matrix help to illustrate knowledge flows and behaviours associated with organizational learning: "The learning matrix provides a means to frame learning as a multi-dimensional, interactive phenomena". (Crossan and Hulland, 1995, p. 10). The framework illustrates distince differences in the levels of learning. Individual level 
learning (cell I-I) is the level educators are most aligned to. The framework identifies groups and organization as valid levels to be isolated and analyzed.

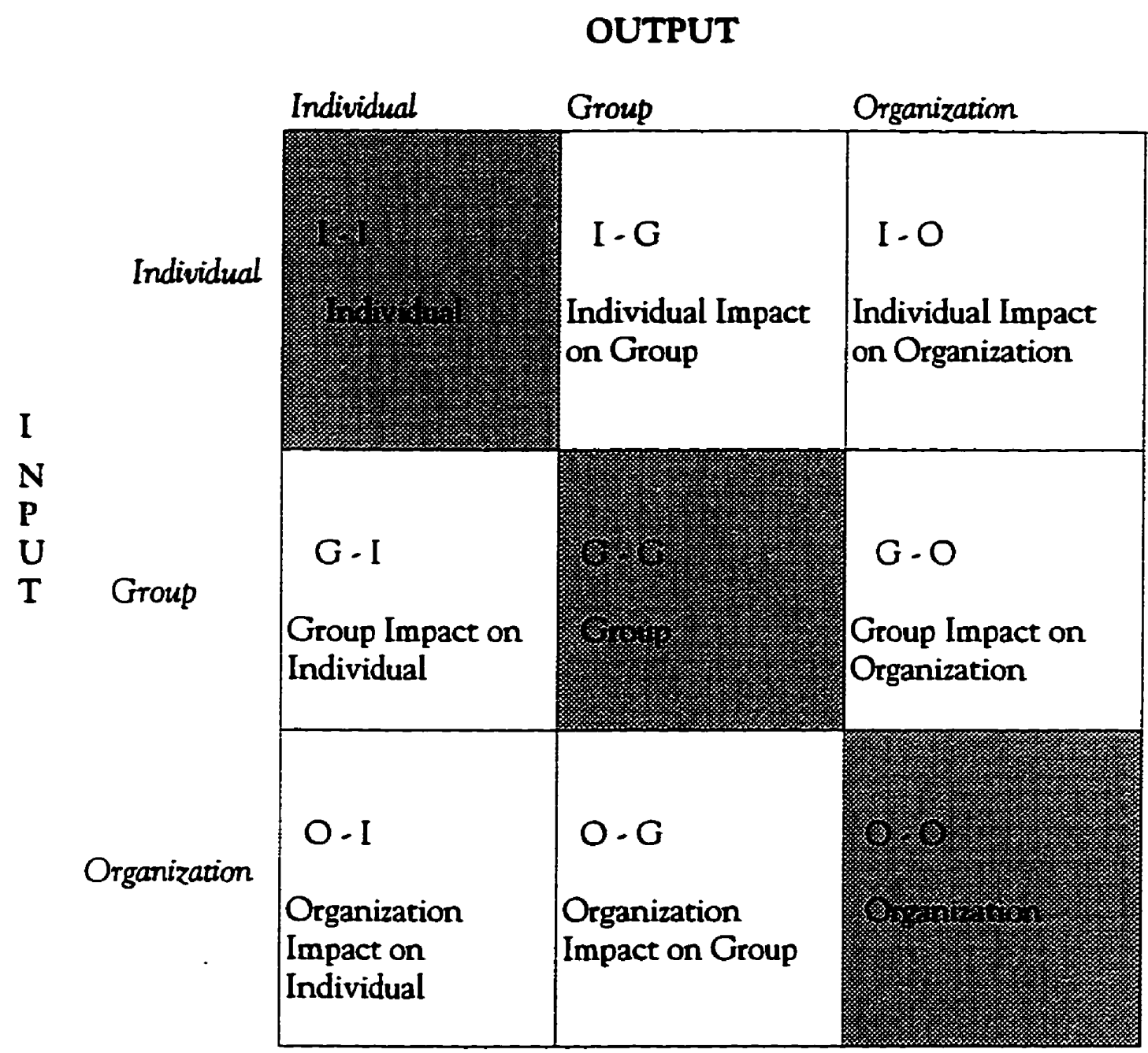

Figure 3.1 The Learning Matrix 
Crossan and Hulland (1996) incorporate the theories of group learning offered by Huber (1991), Senge (1990) and Seely-Brown (1993) and state their view of group learning:

We support the importance of a group level of analysis as distinct from the individual and organization level.... We need to be mindful of the information processing challenges of the group, as well as the issues of interpretation and social construction. And the dominant coalition (leadership) is a group that has particularly strong influence on $\mathrm{OL}$, and thus must also be recognized. (p.5)

At the organization level, the framework captures the "non-human" element and sees the $\mathrm{O}-\mathrm{O}$ cell as representing storehouses of learning. The $\mathrm{O}-\mathrm{O}$ cell depicts organization encoding and institutionalizing in the form of systems, structures, and procedures. Crossan and Hulland (1996) state "the organization level is not just the impact of systems, structures and procedures on learning, it is also the institutionalizing of individual and group learning in the systems, structures and procedures" (p. 6).

\section{Feed-Forward and Feed-Back}

The points of intersection above and below the diagonal represent flows of information between the levels. Below the diagonal, feed-back loops represent the ways in which integrated and institutionalized learning impact the creation, development and integration of insights and new ideas (cells O-G, O-I and G-I). 
Figure 3.2 Feed-Forward and Feed-Back Flows of Learning

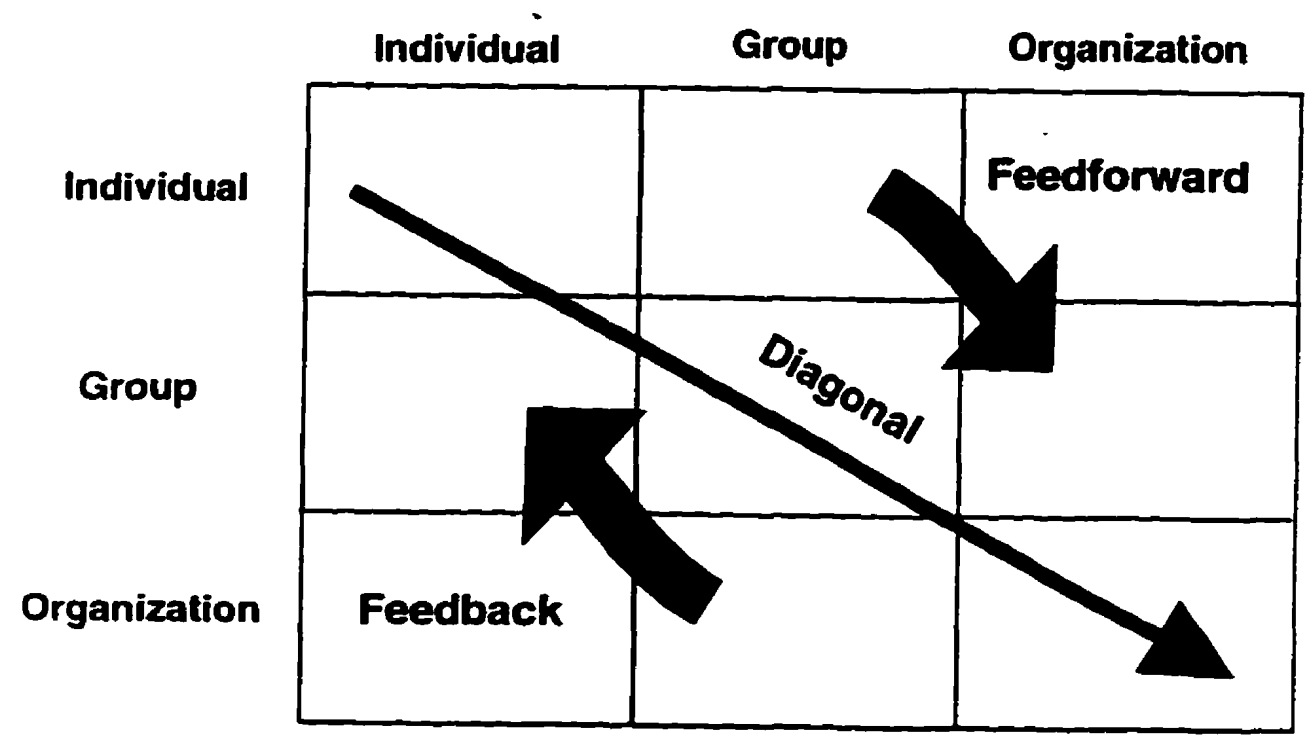

By examining the organization level constructs (systems, structure, strategy, procedures, culture, etc.) and their influence on individual learning, one can determine if institutionalized learning is facilitating individual learning (cell $\mathrm{O}-\mathrm{I}$ ). As discussed in the literature review, the organization may "empower" individuals and enable them to be innovative and intuitive. Organizations may also stifle individual thought and action. Within a single organization, both of these actions may occur; the organizational level could be a hindrance to learning in some situations and a support individual learning in other situations. Cell G-I represents the groups impact on individuals. The group may motivate individual learning by inspiring individuals and enabling them to be innovative and intuitive. As Simon (1995) summarizes: "Group learning can support individual 
learning by creating opportunities to learn, stimulating each other to learn, helping each orher to integrate learning skills in work, giving each other feedback and rewards for learning, helping and supporting each other while learning" (p. 283). Negative tensions between the group level and individual level can also exist -- groups have the potential to stifle individual thought.

The cells above the diagonal (I-G, I-O, and G-O), represent feed-forward loops; the ways in which new ideas and insights become integrated and institutionalized. Senge (1990) sees this flow of leaming as crucial: "Individual change is vital - but not sufficient. If we are going to address these conditions (need for change) in a significant way, it will have to be at the level of collective thinking and understanding" (p. 236).

For individual learning to impact an organization, the learning must eventually be manifested at the organization level. Nicolini and Meznar (1995) assert: "Only learning embedded in standard operating procedures, methods of communication and co-ordination and shared understanding about tasks have a persistent effect." ( p.734) By examining behaviour associated with feed-forward, one can determine how well the organization is perceived to institutionalize the learning of individuals and groups.

\section{Tensions}

The three learning levels and flows of information between them create tensions for learning and these tensions can both help and hinder organizational learning. One example of the challenge of managing the tensions amongst the levels is how to ensure that the context through which new ideas and insights are interpreted by individuals and 
integrated by groups is not impeding growth and the organization's ability to respond to its environment. Crossan and Hulland (1995) define the challenge:

The challenge for organizations is to manage the tension between the institutionalized learning that enables it to efficiently produce along the part of the business that is well defined, and is more routine in nature, while simultaneously allowing the less tangible and concrete process of intuiting, interpreting and integrating to flourish. (p.12)

Information related to behaviour in the feed-forward and feed-back constructs helps one understand the tensions amongst the levels of learning. An important consideration is that tensions amongst levels are not hindering learning. When it is required, institutionalized learning must result in intuition (new ideas) and new interpretations (new ways of looking at things). And, although it is often difficult for intuition to overcome institutionalized learning, when existing processes need radical adjustment, intuition from individuals with the "right" vision must become institutionalized.

Crossan and Hulland (1995) explain the strength of the Learning Matrix over other frameworks in this way:

Most of the existing work in OL can be positioned along the diagonal of the matrix, focusing on the learning process at any one level, such as individual interpretation, group decision making, or organizational systems and 
structures..... It is our belief that in order to properly capture all dimensions of OL, all nine cells must be assessed. ( p. 9)

Through the learning behaviours and processes represented by the nine cells, knowledge is created. Knowledge creation is a desirable outcome of learning behaviours. Lei, Hitt and Bettis (1996) describe knowledge as an "invisible asset" of the organization that is generated through everyday learning behaviours:

Technological and skill accumulation often occurs through "learning by doing" or "learning by using".. firm- specific leaming and skill accumulation may translate into embedded or tacit knowledge that become the basis for sustainable competitive advantage....Many perspectives that dominated the early thinking concerning competitive advantage have their roots in traditional economic theory with emphasis on market power and industry structure as determinants of performance. ... In recent years however, other streams of research emphasizing a "resource-based" or "skill-based" perspective of strategy and organization have evolved to characterize the firm as a collection of unique skills and capabilities that influence the firm's evolution and strategic growth alternatives..... a firm's competitive advantage is derived from it's unique knowledge. (p. 560)

The ongoing development of "unique knowledge" can become a competitive asset that is proprietary to the organization and difficult to imitare by competitors. 
The Learning Matrix positions the traditional, educational view of learning predominantly in the I-I cell of the Matrix. The additional cells of the matrix provide a broader perspective by identifying the additional levels of learning and the learning processes associated with them (integration and institutionalization). The cells above and below the diagonal on the matrix extend our understanding further to consider flows of learning and tensions among the levels. These additional perspectives potentially provide opportunities for educators to expand our options for developing learning abilities in our organizations.

The theoretical discussion is insighrful in that it provides different perspectives. Moving beyond theory to measure the constructs of the Learning Matrix provides data that we can analyze and interpret to get a handle on how measurement can provide further insights.

The items on the Learning Assessment Map help us to diagnose an organization's unique knowledge and learning abilities. The items are presented in the next chapter along with the details of the application of the measurement instrument. 


\section{Chapter 4: Research Procedures}

Four steps define the procedures followed in this study to apply the Learning Assessment Map:

1. Ethical review of research procedures and administration of the

Learning Assessment Map in the organization.

2. Data-entry of the responses for each instrument.

3. Analysis of the results to identify the perceived patterns of learning and widely-held beliefs about learning and relationships between learning and performance.

4. Interpretation of the results.

Each of the steps will be reported in detail starting with the presentation of the Learning Assessment Map and how it was administered.

\section{The Learning Assessment Map}

The Learning Assessment Map was chosen for use in this study because in addition to its strong theoretical base, it was the only instrument inventoried by the ASTD that can provide tests to show reliability and validity of the instrument. In several applications, the measurement instrument has demonstrated strong "goodness-of-fit" measures and strong assessment of reliability, internal consistency and discriminant validity (Crossan and Hulland, 1996). The conclusion from applications of 
the instrument is that it can accomplish what it was intended to do -- identify meaningful patterns of organizational learning. The application of the instrument "provides empirical support for what to date has been a theoretical debate about whether or not multiple levels of OL' need to be considered". (Crossan and Hulland, 1996, p. 23).

The Learning Assessment Map is a questionnaire used to gather perceptions about particular behaviour patterns that correlate to the constructs of the Learning Matrix and widely-held beliefs relative to learning. The questionnaire has a number of items presented as statements that people respond to using a seven point scale ranging from (1) Strongly Agree to (7) Strongly Disagree. Some reverse-scaled questions are used. The Learning Assessment Map was created as a questionnaire for three reasons:

1. It guarantees that the same set of questions is asked of each respondent,

2. It allows the involvement of a very large population, and

3. It is more time efficient to administer than other ways of measuring such as face-to-face interviews.

The items on the Learning Assessment Map are intended to measure everyday learning behaviours related to each of the nine cells of the Learning Matrix. In addition to the nine cells, there are three other categories of items. One additional category isolates information about leadership as a distinct group. A second additional category measures individual perceptions of organizational performance ( to gather information about the relationship between learning and performance). A final set of items collects information about the widely-held beliefs about learning to gather information about the learning climate. To present the items, I have unbundled the sections of the instrument 
to put related items together. The items are presented next in six categories: Individual

Level, Group Level, Organizational Level, Leadership, Cognition, Performance.

\section{Individual Level .}

Statements related to individual learning (cell $\mathrm{I}-\mathrm{I}$ ) measure the pure processes of intuiting and interpretation resulting in individual cognitive and behavioural change. Table 3.3 lists the items to collect information about this construct.

\section{Table 3.3 Items to Collect Information about Individual Learning Behaviours}

1. Individuals generate many new insights.

2. Individuals take actions that are experimental in nature.

3. Individuals are able to break out of traditional mind-sets to see things in new and different ways.

4. Individuals are able to grow through their work.

5. Individuals are aware of the critical issues that affect their work.

6. Individuals accept negative feedback without becoming defensive.

7. Individuals have a clear sense of direction in their work.

8. Individuals feel a sense of accomplishment in what they do.

9. Individuals have a capacity to change and grow with the business.

10. Individuals feel a sense of pride in what they do.

11. Individuals feel a sense of ownership in what they do.

12. Individuals look for new and better ways to work.

13. Individuals are current and knowledgeable about their field of work.

14. Individuals have a high level of energy at work.

15. Individuals feel confident in their work.

16. When individuals make an error they will usually try to cover it up. (reverse scaled)

17. Individuals scan the external environment (customers, suppliers, competitors, governments) to assess future risks and opportunities.

18. Individuals demonstrate a high level of competency in their work.

19. The origin of most of our innovative ideas are people within the organization. 
The statements address issues for learning that have been identified by $\mathrm{OL}$ theorists such as: individual capability and capacity to create new knowledge, accountability for actions, self-reflection, the disciplines of personal mastery and mental models, the behaviours of experimentation, risk taking, learning from mistakes, personal growth and the extent to which individual collect data from the external environment to improve the business.

\section{Group Level Learning}

The focus of cell G-G is group level learning behaviour. Information about the learning disciplines described by Senge: collective mental models, team learning, shared vision and systems thinking are captured in this cell. Items about the process of information sharing help determine how widely information is shared. Table 3.4 lists the items related to the group level construct.

Table 3.4 Items to Collect Information about Group Learning Behaviours

1. Group work in this organization is valuable.

2. Others in the organization co-operate with us in order to share relevant information.

3. Different points of view are encouraged in my group.

4. We have effective resolution of conflict in my group.

5. When we work in groups, ideas arise that did not occur to any one individual.

6. We do not know how to effectively work in groups. (reverse scaled)

7. When working in groups we have the right people involved in addressing the issues.

8. We share our successes with others.

9. We share our failures with others.

10. In meetings, we are prepared to rethink decisions when presented with new information.

11. We have too many unproductive meetings (reverse scaled).

12. In meetings, we seek to understand everyone's point of view. 


\section{Organization Level}

The process of institutionalizing is the focus of items related to this cell. As described earlier, this cell is most easily conceptualized as being "non-human" elements of organizational learning. The items are designed to capture perceptions about the storehouse of knowledge in organizational structure, culture, vision, strategies and systems of the organization. The willingness of the culture to accept risk-taking and experimentation is captured in the words "trust" and "innovation". The items address the ability of systems to capture and store information. Respondents are asked if the performance indicators are perceived to be relevant as they can drive the behaviours of individuals and groups.

Table 3.5 Items to Collect Information about the Organization

1. The organizational structure supports our strategic direction.

2. We have a strategy that positions us well for the future.

3. We have a realistic yet challenging vision for the organization.

4. We have an organizational structure characterized by a high degree of trust.

5. The organization culture could be characterized as innovative

6. We are a learning organization.

7. Our information systems are "leading edge".

8. We have systems in place that enable us to keep track of the critical issues that affect our business.

9. We have relevant performance indicators for our business.

10. Our organizational structure needs to be reassessed. (reverse scaled)

11. Our physical assets are inadequate (i.e., buildings, furniture). (reverse scaled)

At each of the levels of learning, items measure the "stocks" of learning: "For example, stocks of learning at the organization level - such as systems, structures, strategy and culture - support or impede the process of individual and group learning. Stocks also exist 
at the individual level (e.g., level of competency, individual orientation to experiment).

... the initial stock of leaming at the individual, group and organization levels; 1) impacts

the flow or process of learning; and 2) is transformed in the process. "(Crossan and

Hulland, 1996, p.15). The flows of learning are measured by the items related to

feed-forward and feed-back which are presented next.

\section{Feed-Forward}

The items related to feed-forward are listed on Table 3.6

Table 3.6 Items to Collect Information about Feed-Forward Behaviours

1. We rarely think or act beyond the boundaries of our own jobs. (reverse scaled)

2. Individuals are prepared to challenge the assumptions of the group.

3. Individuals posses the appropriate communication skills to contribute to the group process.

4. Individuals are discouraged by the resistance they receive from others when trying to affect change. (reverse scaled)

5. Individuals are reluctant to share their ideas with others. (reverse scaled)

6. We share new insights throughout the organization.

7. This organization captures the intelligence of its workforce

8. Individuals understand how their work contributes to the performance of the organization.

9. We routinely communicate the lessons learned from our past actions throughout the organization.

10. New insights get developed into the improved products or processes.

11. We seem to continually "reinvent the wheel." (reverse scaled)

12. There are good ideas that seem to go nowhere. (reverse scaled)

13. When a good person leaves the organization, we lose valuable information. (reverse scaled)

14. Individuals have input into our strategy.

15. We propose innovative solutions to organization-wide problems.

16. The decisions we make are reflected in changes to our organizational systems and procedures.

17. No matter what we do, the organization does not seem to change. (reverse scaled) 
The ease with which the individual level learning is translated into changes at the group and organization level gives some indication of how well the organization is perceived to capitalize on the learning of individuals and groups.

Feed-Back

The set of items related to the feed-back behaviours are given in Table

\section{7 .}

Table 3.7 Items to Collect Information about Feed-Back Behaviours

1. Individuals know enough about the work of others to be able to pass on the information they need.

2. Individuals take the needs of other members of the group into account when making decisions.

3. Once the group has made a decision, individuals will support it.

4. Individuals comply too easily with directives. (reverse scaled)

5. In meetings, we have access to the right information to make the best decisions.

6. When making decisions for the future, we do not seem to have a memory of the past.(reverse scaled)

7. Valuable information from success or failure of past programs is not available. (reverse scaled)

8. Reward systems recognize the contribution made by groups.

9. Our information systems make it easy for individuals to share information.

10. Our organizational structure facilitates the sharing of ideas.

11. Individuals understand the vision and strategy of the organization.

12. Individuals are directed by the vision and strategy of the organization.

13. Time for learning is readily available to all individuals.

14. Resources for learning are readily available to all individuals.

15. Our systems and procedures support innovation.

16. Our policies and procedures aid individual work.

17. Cross training, job rotation and ad hoc assignments are used to develop a more flexible workforce.

18. Our compensation structure rewards people appropriately.

19. Our compensation structure motivates people appropriately.

20. Training is readily available when it is needed to improve knowledge and skills.

21. Our policies and procedures of the organization block new ideas. (reverse scaled)

22. Our organizational structure enables the right people to deal with the right problems.

23. We recruit the best people in the industry.

24. Key information is readily available through our information systems. 
The items collect information about the perceptions of the existence of a learning infrastructure that includes conditions and enablers for learning at the individual and group levels. Items collect information about the existence of a common sense of purpose that comes from a well articulated and achievable vision statement and related strategies. The items also collect information about reward and recognition, compensation, employee development and education practices. The items can help us discover if the organization is attracting and keeping good people (building human capital and capacity) and directing their actions toward common goals which facilitates focused learning.

\section{Cognition}

It has been argued in the discussion of the cognitive/behavioural change matrix (figure 2.1) that cognitive learning and behaviour change are separate processes. The items on table 3.9 list the perceived cognition the instrument measures.

Table 3.9 Items About Cognition Relative to Learning

Individual Cognition
1. We value creativity.
2. Experimentation is necessary for learning.
3. Making mistakes is part of learning.
4. It is important to be open-minded.
5. It is important to feel fulfilled by your work.
Feed-forward Cognition
6. Innovation is taking a good idea and making it happen.
7. It is important to capitalize on a good idea.
8. Individuals can make a difference.
9. It is important to share our ideas with others.
10. Others can learn from our successes and failures.
11. To contribute to others, we need to be aware of their needs and
issues.
Group Cognition
12. Diversity is important.
13. Open communication is critical.
14. Teamwork is an essential part of organizational activity.


The statements collect information about the widely-help beliefs about learning. As revealed in the literature review, theorists have described a number of beliefs important for the organization that is constantly learning: creativity, experimentation, learning from mistakes, self-reflection, integrating diversity, and sharing information.

\section{Leadership}

The Learning Assessment Map collects information about leadership as an isolated category at the group level and assesses the perceived effectiveness of management behaviours to facilitate feed-forward and feed-back of learning. Table 3.8 lists the items related to leadership behaviours.

\section{Table 3.8 Items Relative to Leadership as a Catalyst for Learning}

\section{Feed-forward Leadership}

1. Management supports the learning and development of individuals.

2. Management encourages experimentation and innovation.

3. Decisions made by the management team have a strong impact on what individuals do.

4. Decisions made by management are well communicated to the workforce.

5. Individuals feel well served by management.

6. Individuals feel they have input into the critical decisions made by management.

7. Management actions are in keeping with the stated vision.

8. Management demonstrates the leadership qualities required to excel. Feed-back Leadership

9. The management team has articulated a clear strategic direction.

10. The management team has developed a clear vision.

11. The management ream drives change in the organization.

12. Management actions support the strategy.

13. Management understand the challenges facing individuals in this organization.

14. Individuals understand how what they do fits into the decisions made by management.

Leadership

15. Management continually ensures that new knowledge and information are disseminated to all parts of the organization.

16. Management works as a team. 


\section{Performance}

One of the assumptions underlying the Learning Assessment Map is that learning and performance are not directly and positively linked. A desirable outcome of learning is improved performance but this link must be managed. There is a strong connection between perceived performance and financial performance (Geringer and Hebert, p. 240). Therefore the responses to subjective performance items give some indication of financial performance of the organization. When the results are analyzed, conclusions can be drawn about how perceived learning patterns impact performance.

\section{Table 3.10: Items to Collect Information about Performance}

1. We understand and meet our external customer needs.

2. We understand and meet our internal customer needs.

3. Employees are very satisfied working here.

4. We provide a good return to our shareholders.

5. Individuals are generally satisfied with their performance.

6. Individuals are fulfilled by their work.

The complete measurement instrument is shown in Appendix 1. The value judgements prompted by the wording of many of the items on the measurement instrument mean that rather than purely measuring learning patterns, the items measure perceptions of whether or not certain learning behaviours and flows of learning are occurring. The measurement instrument provides valuable information about how well people believe flows of learning are occurring. The value dimension allows one to draw conclusions about effectiveness of certain dimensions within each of the categories of results. For example, the low score for questions about the organization level affect on individual leaming indicates that this feed-back flow does not have appropriate impact on 
individuals. As an example, a low score for "Our systems and procedures support innovation" does not give pure information about the impact of systems and procedures on innovation - it tells us that individuals do not value the impact systems and procedures have.

Many of the ideas embedded in the items of the Learning Assessment Map are intuitive and may, at first, seem outside of the realm of learning (e.g., vision, strategy and structure are part of a learning infrastructure; processes for sharing information among groups support learning, communities of practice are communities of learning; when good people leave an organization, valuable information is lost; and organizations have memories that exist even though organization members come and go). However, when the various ideas about $\mathrm{OL}$ are brought together and discussed in the context of the Learning Matrix and the Learning Assessment Map, we can begin to visualize more concretely what $\mathrm{OL}$ can be. The Learning Assessment Map items add insights into identification of behaviours, characteristics, cognition and conditions of $\mathrm{OL}$. The discussion lends credibility to the belief that there is not a "blueprint" for a learning organization. The relative strength of the levels of learning and fluidity of learning between the leveis can vary depending on the needs of the organization. In thinking about the organizations we work in: private businesses or schools, we can start to appreciate that there is benefit to looking at learning from the $\mathrm{OL}$ perspective.

In the next section the participating organization is described followed by the procedures followed to administer the measurement instrument. 


\section{Participating Organization}

The organization participating in the research is Strategic Business Unit of a large corporation. The organization sells products directly to external customers and services the distribution network of the corporation. The organization works within a highly regulated industry but has some ability to vary the product features to customize it for the organization. The organization has 175 staff working in eight departments. More than half of the staff are administrative or customer service clerks and have fairly routine jobs. These staff are serving internal and external customers. The issues that arise are, for the most part, predictable and documented policies and procedures are in place to deal with them. If issues arise that are out of the ordinary, the clerks are expected to deal with the issues themselves or go to a supervisor for help. The structure is hierarchical. The organization is headed up by a Vice- President and two Assistant Vice Presidents. A level of middle managers report to the senior management. Supervisors report to each manager and clerks report to the supervisors. Job expectations are documented and an annual performance review process takes place.

In the Product Development department, the job levels are the highest of all the job levels in the department. The catalyst for new product development is changes observed or anticipated in the competitive marketplace or responding to customer demands.

The organization has well articulated, written, vision, mission and strategy statements. The profits of the organization are a large source of revenue for the larger corporation. The organization has been in existence for sixteen years. In the first years of 
its existence, the organization experienced some development challenges as it learned how to attract profitable customers and keep them, and learned to stay out of product lines that were not profitable. The most recent five years have been a time of consolidation, streamlining of procedures, and developing a greater understanding of internal and external customers and the business. The industry the organization operates in is highly competitive and growing.

\section{Procedure}

Managers of each department within the organization notified all individuals in their department via electronic mail to tell them that they would receive the questionnaire and could take the necessary time at their desks to complete the questionnaire. Copies of the measurement instrument were then sent to each manager for distribution to all staff (including the managers). A mailing label allowed respondents to send it directly to me. The first page of the questionnaire explained what the study was about, defined terms used and gave directions for returning it. Individuals were not required to identify themselves and anonymity of results was assured.

Ten working days were given to respond to the items and return the instrument. After 10 days, the departmental manager sent a reminder note to their staff asking them to complete the questionnaire if they had not already done so. After the three week period, 93 completed questionnaires were received giving a response rate of $54 \%$. 
We now turn to a discussion of the empirical results from the organization in order to make more conclusive statements relative to the utility of using the Learning Assessment Map to further our understanding of how to identify, diagnose and leverage the OL perspective. . 


\section{Chapter Five: Results}

In this chapter, the results from the administration of the Learning Assessment Map are presented and analyzed. The discussion of results includes suggested priorities for improving $O L$ and ideas for interventions the organization might consider.

\section{Interpretation Concepts Employed}

The results are analysed and interpreted on a number of dimensions:

1. Correlation of performance scores with scores for each construct,

2. Overall patterns of learning,

3. Leadership,

4. Cognition-behaviour gaps.

Each dimension is analyzed based on the mean scores (average score) for each construct and each item. Each respondent assigned a value from 1 (Strongly Disagree) to 7 (Strongly Agree) to each item. The mean scores were produced by entering all the data onto an Excel spreadsheet and using a software - Statistical Package for the Social Sciences (SPSS) to calculate the means and standard deviations for each item and each construct. The mean score for each construct and each item is presented in tabular form within this discussion. For standard deviations for all items, please refer to Appendix 2.

To interpret the results, four was considered a neutral response. Scores above four indicate that, on average, people agree with the statement. Scores below four indicate that, on average, people disagree with the statement. 
Within the discussion, linkages are made between results and possible interventions to consider how the organization can improve organizational learning. In order to decide their course of action, the people in the participating organization will be coached to interpret the results within the context of their history, environment, and current and future strategies.

The construct level results are presented on table 5.1. The interpretation of the results begins with a discussion of the correlation of construct scores with the performance scores.

Table 5.1: Construct Level Results

\begin{tabular}{|c|c|c|c|}
\hline Construct & $\begin{array}{l}\text { Mean and } \\
\text { Std. } \\
\text { Deviation }\end{array}$ & $\begin{array}{l}\text { Correlation with } \\
\text { Performance }\end{array}$ & $\begin{array}{l}\text { Ranking of } \\
\text { Correlation }\end{array}$ \\
\hline \multicolumn{4}{|l|}{ Behavioural } \\
\hline Individual & $\begin{array}{lll}4.57 \backslash & 1.34\end{array}$ & 0.73 & 4 \\
\hline Group & $4.72 \backslash 1.32$ & 0.72 & 5 \\
\hline Organization & $4.48 \backslash 1.29$ & 0.79 & 1 \\
\hline Feed-Forward & $4.3 \backslash 1.36$ & 0.63 & 8 \\
\hline Feed-Back & $4.28 \backslash 1.44$ & 0.74 & 3 \\
\hline \multicolumn{4}{|l|}{ Leadership } \\
\hline Feed-Forward & $4.55 \backslash 1.29$ & 0.7 & 7 \\
\hline Group & $\begin{array}{lll}4.52 \backslash 1.33 & 1.3\end{array}$ & 0.72 & 6 \\
\hline Feed-Back & $4.53 \backslash 1.42$ & 0.77 & 2 \\
\hline \multicolumn{4}{|l|}{ Cognition } \\
\hline Individual & $5.24 \backslash 1.37$ & 0.54 & 10 \\
\hline Feed-Forward & $5.51 \backslash 1.3$ & 0.55 & 9 \\
\hline Group & $5.55 \backslash 1.45$ & 0.52 & 11 \\
\hline
\end{tabular}




\section{Correlation of Performance with the Construct Means}

The scores for the items about respondent's perceptions of organizational performance relative to customers, employees and shareholders were compared to the scores for each construct to determine relationships between the constructs and performance. The correlation with performance gives us some indication of which constructs may be most closely linked with performance.

The values for correlation $(r)$ indicate the statistical relationship of each construct with performance. The value of 1 indicates a perfect correlation. The values indicate the degree of connection between the two variables. The value of $(r)$ gives some indication that the variables tend to move together or in opposite directions. The closer the (r) value is to 1 , the greater the systemic connection between changes in one variable and the other. This information is valuable to the organization trying to prioritize the interventions they will put in place to improve organizational learning.

The results show that for the participating organization, the six constructs most highly correlated with performance are the organization level (.79), feed-back behaviours $(.74)$, leadership feedback behaviours (.77), the individual level behaviours $(.73)$ the group level behaviours (.72) and leadership (.72). The constructs less highly correlated with performance are all of the cognition measures and feed-forward behaviours.

\section{The Three Levels of Learning}

The first step in identifying the organization's overall learning patterns is a discussion of scores for the learning behaviours at the three levels of learning as shown on Table 5.1. Comparing the scores for pure individual (4.57), group (4.72) and organization (4.48), it is at 
the group level that the learning behaviours are perceived to be the strongest. An analysis of the results for each level gives us some indication of the "stocks" for learning.

The results for each item in the individual level construct is given in Table 5.2.

Table 5.2: Individual Level Scores

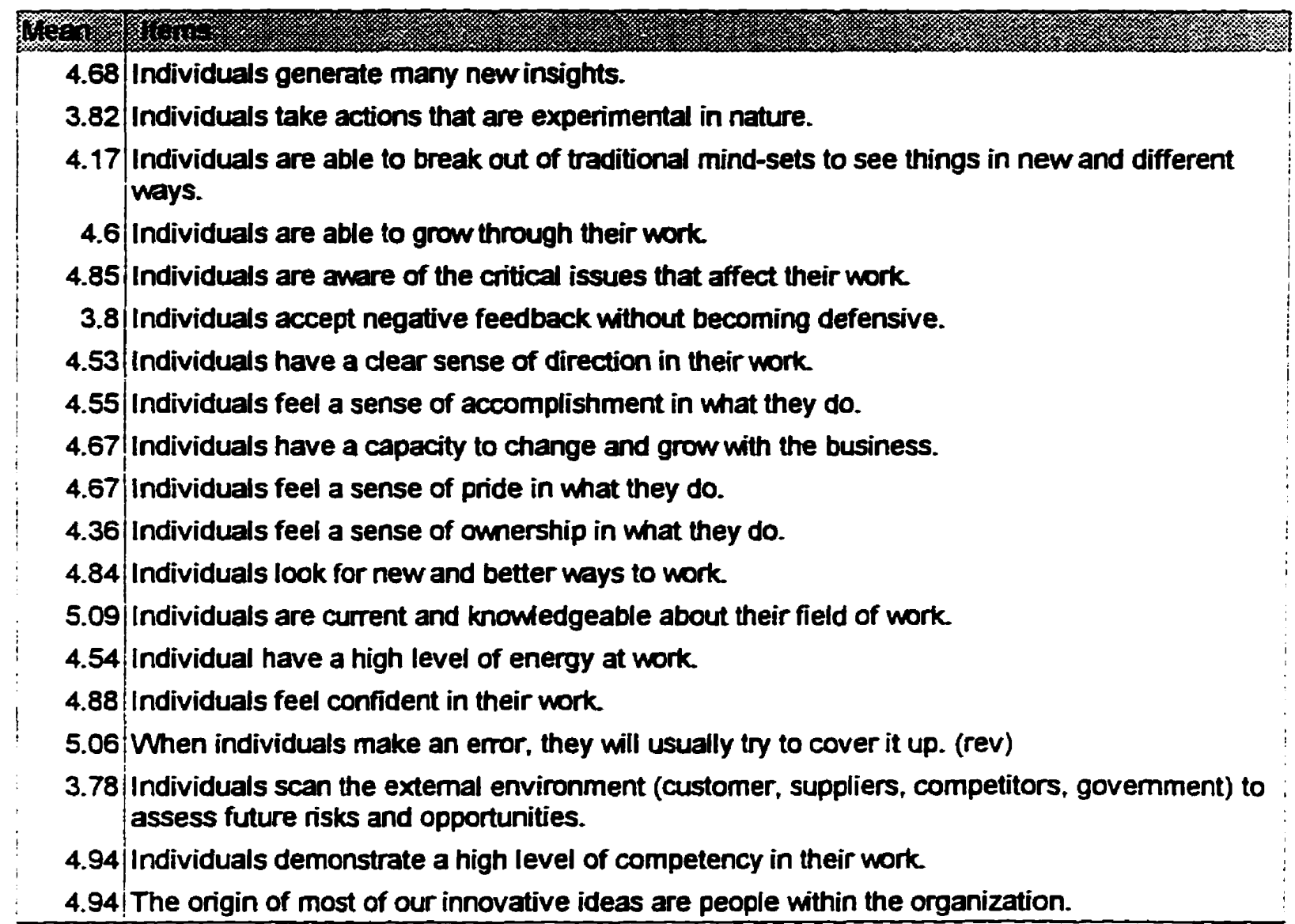

The strongest behaviours related to the Individual level are task- related knowledge, innovation, competency, confidence and awareness of the issues that affect individuals.

Individuals are not perceived to strongly participate in behaviours such as experimentation, learning from mistakes, learning through negative feedback and being creative. The disciplines 
of challenging personal mental models and the process of acquiring knowledge through scanning the environment are not perceived to be strong. The results suggest that task-related learning has been effective in this organization. People seem to feel that, on average, they have the knowledge and skill to confidently do their work. However, demonstration of every-day learning behaviours are not perceived to be strong.

An analysis of the group level items indicates that group dynamics and shared understanding are relatively strong. Individuals perceive group level strengths to be synergy, relatively strong skills of group work, and encouraging and considering new ideas. The following statements received the highest scores for the GG caregories: "When we work in groups, ideas arise that didn't occur to one individual", "We know how to effectively work in groups", "We share our successes with others", and "In meetings, we are prepared to re-think decisions when presented with new information". The group level results are presented in Table 5.3.

\section{Table 5.3: Group Level Scores}

\begin{tabular}{|l|l|}
\hline 5.43 & Group work in this organization is valuable. \\
4.52 & Others in the organization co-operate with us in order to share relevant information. \\
4.67 & Different points of view are encouraged in my group. \\
4.38 We have effective resolution of conflict in my group. \\
4.94 When we work in groups, ideas arise that did not occur to any one individual. \\
5.17 We do not know how to effectively work in group. (rev) \\
4.49 When working in groups we have the right people involved in addressing the issues. \\
4.84 We share our successes with others. \\
4.36 We share our failures with others. \\
4.79 In meetings, we are prepared to rethink decisions when presented with new information. \\
4.39 We have too many unproductive meetings. (rev) \\
4.67 In meetings, we seek to understand everyone's viewpoint. \\
\hline
\end{tabular}


As discussed in the literature review, groups can be powerful learning entities. There is also the possibility that relying too heavily on group work could atrophy the ability of individuals to have impact. The organization may need to consider if it needs to further build the strengths of learning done through groups. The organization may decide that the group level is strong enough and it is important to ensure the individual level is equally as strong a stock of learning. If the decision is made to improve group level learning, this organization should focus on the weakest group learning behaviours of sharing lessons learned from failures, having the right people involved in groups, and using conflict in the most productive ways.

The lower score (4.48) for the organization level indicates that it may not be a strong storehouse of knowledge. The low score could be problemaric, especially given this level's high correlation to performance. To determine which aspects of this level are in most need of improvement, each item and score given in table 5.4 must be analyzed. The strongest aspects of the organization level are relevant performance indicators, adequate physical assets, structure and vision and strategy that are challenging and well positioned. The weakest aspects of this level are information systems that are "leading edge", systems that enable tracking of critical business issues and a culture that is considered trusting.

Information systems can be a catalyst for learning flow when they are designed, managed and used effectively. The results reveal that individuals do not perceive information systems to be "leading edge" in this organization. 
Table 5.4: Organization Level Scores

\begin{tabular}{|r|l|r|}
\hline 4.54 & The organizational structure supports our strategic direction. \\
4.63 & We have a strategy that positions us well for the future. \\
4.64 & We have a realistic yet challenging vision for the organization. \\
4.35 & The organization culture characterized by a high degree of trust. \\
4.6 & The organization culture could be characterized as innovative. \\
4.74 & We are a "leaming Organization". \\
3.98 & Our information systems are "leading edge". \\
4.43 & We have systems in place that enable us to keep track of the critical issues that affect our \\
4.72 & business. \\
4.1 & Our organizational structure needs to be reassessed. (rev) \\
3.43 & Our physical assets are inadequate (i.e., buildings, furniture). (rev) \\
\hline
\end{tabular}

Fostering a culture open to innovation and risk-taking, and creating a more advanced information system are two interventions that might improve the learning stock at the organization level. Developing a climate of trust can have an impact on other components of the patterns such as improving some of the weaknesses of individual and group learning: accepting negative feedback, being willing to experiment and sharing lessons learned from failure.

\section{Feed-Forward Learning Flow}

The scores related to feed-forward indicate whether individual learning feeds forward into group learning and if both individual and group learning impact the organization in terms of changes to structure, strategy, culture, systems and procedures.

As shown in Table 5.1, the score for the construct is 4.30. A look at the results for each feed-forward item (Table 5.5) indicares some relative strengths in this flow: individuals 
understand how their work contributes to the performance of the organization (which is important for focusing people's efforts to an overall goal); individuals have good communication skills to contribute to the group process; and new insights are shared and get developed into improved products or processes.

\section{Table 5.5: Feed-Forward Behaviour Scores}

\begin{tabular}{|r|r|r|}
\hline 4.24 & Individuals tend to act in their own self interest. \\
4.43 & We rarely think or act beyond the boundary of our oun jobs. \\
4.37 & Individuals are prepared to challenge the assumptions of the group. \\
4.8 & Individuals possess the appropriate communication skills to contribute to the group process. \\
3.9 & Individuals are discouraged by the resistance they receive from others when trying to affect \\
\hline 4.6 & change. (rev) \\
4.62 & Individuals are reluctant to share their ideas with others. (rev) \\
4.15 & This organization captures the intelligence of its workforce. \\
4.84 & Individuals understand how their work contributes to the performance of the organization. \\
4.21 & We routinely communicate the lessons leamed from our past actions throughout the \\
\hline 4.63 & Nrganization. \\
3.74 & Wew insights get developed into improved products or processes. \\
3.82 & There are good ideas that seem to go nowhere. (rev) \\
2.79 & When a good person leaves the organization, we lose valuable information. (rev) \\
3.93 & Individuals have input into our strategy. \\
4.05 & We propose innovative solutions to organization-wide problems. \\
4.38 & The decisions we make are reflected in changes to our organizational systems and \\
\hline 4.86 & procedures. & No matter what we do, the organization does not seem to change. (rev) \\
\hline
\end{tabular}

In contrast to the areas of relative strength, the results indicate that respondents perceive that the intelligence of the workforce is not being captured and embedded at the organization level and "when a good person leaves the organization, valuable information is 
lost". Individuals believe they do not have input into strategy which can be a critical factor for achieving buy-in to strategy. There are some apparent contradictions in the results; in contrast to relatively high scores for sharing insights and insights being used, the score for "innovative solutions are proposed to organization-wide problems" is relatively low. The items give some indication of opportunity to improve feed-forward behaviours but this organization may want to focus on the improvement of feed-back behaviours. As revealed in Table 5.1, feed-back is more highly co-related to performance and received a lower mean score than feed-forward.

\section{Feed-Back Learning Flow}

The scores related to feed-back indicate how well the organization uses the learning embedded in the systems, structures, strategy, procedures and culture of the organization to facilitate learning at the individual and group levels and if group learning feeds-back to the individual.

The overall feed-back score (4.27) is lower than the feed-forward score. The scores for each item is given in Table 5.6. An analysis of the items and scores reveals that the organizational framework for learning is not perceived to be facilitating individual learning behaviour to a great degree.

The strongest feed-back elements are a good understanding at the individual level of the organizational vision and strategy, and individual support of group decisions. There is a discrepancy between individual understanding of the vision and strategy and being directed by the vision and strategy. This may indicate that something is blocking people's ability to line up their actions with the organizational direction. 
The components of feed-back that received the lowest scores were: time and resources for learning; a compensation structure that rewards and motivates individuals and groups; systems and procedures that support innovation, recruiting, access to necessary information, an organizational structure that allows the right people to deal with problems and the ready availability of training.

Table 5.6: Feed-Back Behaviours Scores

\begin{tabular}{|c|c|}
\hline 5 & 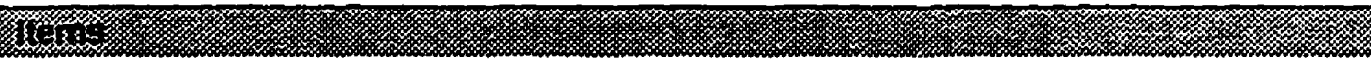 \\
\hline 4.58 & Individuals understand the vision and strategy of the organization. \\
\hline $4.38 \mid$ & Individuals are directed by the vision and strategy of the organization. \\
\hline 3.29 & Time for leaming is readily available to all individuals. \\
\hline 3.85 & Resources for learning are readily available to all individuals. \\
\hline 4.01 & Our systerns and procedures support innovation. \\
\hline 4.27 & Our policies and procedures aid individuals work. \\
\hline 4.07 & $\begin{array}{l}\text { Cross training, job rotation and ad hoc assignments are used to develop a more flexible } \\
\text { workforce. }\end{array}$ \\
\hline 3.43 & Our compensation structure rewards people appropriately. \\
\hline 3.38 & Our compensation structure motivates individuals appropriately. \\
\hline 3.99 & Training is readily available when it is needed to improve knowledge and skills. \\
\hline 4.51 & Our policies and procedures of the organization block newideas. (rev) \\
\hline 4.24 & Our organizational structure enables the right people to deal with the right problems. \\
\hline 4.18 & We recruit the best people in the industry. \\
\hline 4.36 & Key information is readily available through our information systems. \\
\hline 4.35 & In meetings, we have access to the right information to make the best decisions. \\
\hline 4.78 & $\begin{array}{l}\text { When making decisions for the future, we do not seem to have a memory of the past. } \\
\text { (rev) }\end{array}$ \\
\hline 4.88 & Valuable information from success or failure of past programs is not available. (rev) \\
\hline 3.92 & Reward systems recognize the contribution made by groups. \\
\hline 4.44 & Our information systems make it easy for individuals to share information. \\
\hline 4.45 & Our organizational structure facilitates the sharing of ideas. \\
\hline 4.19 & $\begin{array}{l}\text { Individuals know enough about the work of others to be able to pass on the information } \\
\text { they need. }\end{array}$ \\
\hline 4.28 & $\begin{array}{l}\text { Individuals take the needs of other members of the group into account when making } \\
\text { decisions. }\end{array}$ \\
\hline $\begin{array}{r}4.59 \\
4.2 ! 1\end{array}$ & $\begin{array}{l}\text { Once the group has made a decisions, individuals will support it. } \\
\text { Individuals comply too easily with directives. (rev) }\end{array}$ \\
\hline
\end{tabular}


Leadership

Leadership and management practices greatly influence learning on all three levels.

Analysis of the perceptions of management as a catalyst for learning on the individual, group and organization levels is done using the scores for items in three categories; leadership feed-forward (4.55), leadership group construct (4.52), and leadership feed-back (4.53). The scores for each of the leadership items are given in Table 5.7. The leadership of the participating organization received fairly high scores at the construct and item levels relative to the other constructs.

Table 5.7: Leadership Behaviours Scores

4.52 Management continually ensures that new knowledge and information are disseminated to all
parts of the organization.
4.51 Management works as a team.
Leadership Feed-forward Behaviours
4.45 The management team has articulated a clear strategic direction.
4.52 The management team has developed a clear vision.
5 The management team drives change in the organization.
4.8 Management actions support the strategy.
4.15 Management understands the challenges facing individuals in this organization.
4.35 Individuals understand how what they do fits into the decisions made by management.
4.59 Management encourages experimentation and innovation.
5.55 Decisions made by the management team have a strong impact on what individuals do.
Leadership Feed-back behaviours
4.45 Decisions made by management are well-communicated to the workforce.
3.52 Individuals feel they have input into the critical decisions made by management.
4.7 Management actions are in keeping with the stated vision.
4.67 Management demonstrates the leadership qualities required to excel.


The leadership categories are relatively highly correlated with performance. The feed-back category is the most highly correlated with performance of the leadership caregories (see Table 5.1). Some opportunities to improve leadership as a catalyst to the feed-back of learning are revealed in the items that received the lowest scores within the leadership feed-back category: "Individuals feel they have input into the critical decisions made by management", "Decisions made by management are well-communicated to the workforce", and "Individuals feel well-served by management". If the organization decides it is a priority to strengthen the management constructs, the results show that behaviour can be improved in the areas of capturing and using individuals' ideas and facilitating the flow of information between individuals and groups.

\section{Cognition-Behaviour Gaps}

The cognition-behaviour gap is the difference between the mean scores for cognition items and behaviour items. A large gap between cognition and behaviour indicates that something is blocking employee's ability to behave in line with their beliefs and achieve "integrated learning" (the desirable state of both cognitive and behavioural change and actions being in line with beliefs). The results for each of the items in the cognition category are given in Table 5.8 and the gaps calculated for the participating organization are listed in Table 5.9 .

It is interesting to note in Table 5.8 that the cognition measures that received the lowest scores measure the beliefs about the learning behaviours that were found to be weak at the individual level: making mistakes in order to learn, creativity and experimentation. Since 
individuals do not have relatively strong beliefs in these areas, we can see that they do not practice them to a great degree.

\section{Table 5.8 : Cognition Scores}

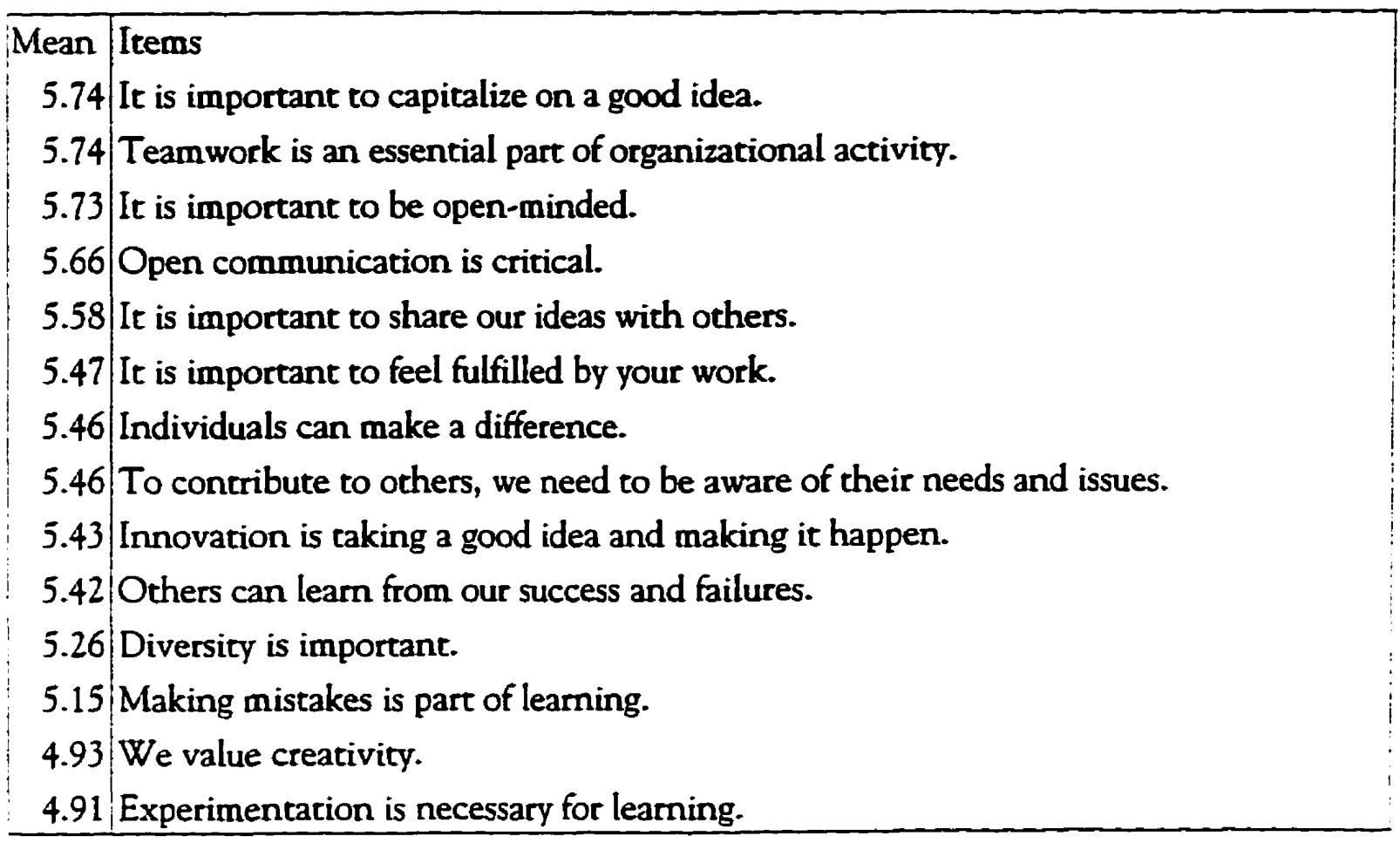

An analysis of the gaps between cognition and behaviour (Table 5.9) shows an overall gap of 1.07 . The smallest gap is between cognition and behaviours in the individual level construct (gap of .68). Large gaps exist between the beliefs and behaviours related to the feed-forward of learning (1.07).

Significance tests done on each of the sets of means determine if the gaps between them are statistically significant. A calculation of $t$-score for a two tailed test at the $5 \%$ level of significance revealed that a difference between the means for the individual level behaviours and cognition of .39 or greater is statistically significant. The same test applied to the group 
and feed-forward means showed that the difference between means of group behaviours and group cognition is significant at .40 . The difference between means of more than 39 is statistically significant between feed-forward behaviours and feed-forward cognition.

Table 5.9: Cognition/Behaviour Gaps

\begin{tabular}{|lc|}
\hline Individual Cognition & \multicolumn{2}{c}{5.24 Gap $=.68$} \\
Individual Behaviours & 4.56 \\
Group Cognition & 5.5 \\
Group Behaviours & 4.72 Gap $=.83$ \\
Feed-forward Cognition & 5.51 \\
Feed-forward Behaviours & 4.3 \\
Gap $=1.21$ \\
9.
\end{tabular}

The significant gaps between cognition and behaviours indicate that individuals value certain behaviours they are not putting into practice. Blockages may exist that do not allow the level of learning and flows of knowledge which people believe are important. The feed-forward gaps are larger than the individual and group gaps. This indicates that people believe they should have more impact on the group and organization levels than they perceive they have. 
The organization could achieve a higher degree of "integrated learning" if beliefs were more in line with behaviours. Identifying the reasons for barriers to behaving in line with beliefs such as why individuals perceive they are "continually re-inventing the wheel" and why "good ideas go nowhere" will help the organization determine how to eliminate the bartiers.

\section{Improving Learning Patterns}

The results have illustrated that the scores for the behaviours at the three levels of learning are higher than the scores for both feed-forward and feed-back behaviours (see Table 5.1). This imbalance in the scores indicates that individual competency and capability and group level learning may exceed the organization's ability to utilize it. There are bottlenecks to the flow of learning as indicated by the lower scores for feed-forward and feed-back.

The organization needs to consider where scarce development dollars can be best spent. A traditional corporate education approach would be to invest in individual or group learning behaviours. The results seem to indicate that for this organization, investment in individual competencies and group learning abilities have been relatively effective. Putting more investment into these levels of learning may not yield better performance because of the bottlenecks to using new skills and knowledge. Resources may best be directed to strengthen the organization level, feed-back and feed-forward constructs before any more effort is put into individual or group learning abilities.

The analysis suggests that to improve overall learning patterns and impact performance, this organization has three leverage points:

1. Improve the organization level as a storehouse for learning. 
2. Improve the balance of flows of learning with emphasis on strengthening the feed-back flows.

3. Narrow the cognition/behaviour gaps.

The results give indications of where to focus to improve OL but we would need to do more investigation of the blockages to flows of leaming and the details of learning impediments at the organizational level in order to develop programs to address the problem areas. There are a number of resources available from many areas of management and business practice to help in the decisions about programs to improve the three areas. Some suggestions are listed here to illustrate the types of programs that may be considered and to contrast them with traditional education and training and development solutions.

\section{Improve the Organization Level as a Storehouse for Learning}

Organizations with this developmental need might conduct an audit of the organization level elements to determine their utility to capture and store knowledge and allow it to be easily retrieved. The audit would include an examination of compensation, reward and recognition and training policies, procedures, systems, culture, etc. to assess the impact of these elements on the flow of learning. The auditor would require an understanding of the organization in terms of strategy, the industry in which the organization operates, and the roles of all staff to assess the elements and suggest improvements.

Training and development methodologies may need to build more on the awareness of the reasons for change. The limitations of methodologies directed towards "forced" or "anticipatory" learning must be understood and avoided. 
With the perception that the culture is not trusting and does not support important learning behaviours such as experimentation, making mistakes and learning from failures as well as success, there may be blockages to learning. The leadership can be instrumental in improving these cultural aspects through role modelling, reward systems and consistent, organization-wide communications about organizational values.

\section{Improve the balance of flows of learning}

The primary blockages indicated by the results are how individual learning affects organizational change and how the organizational structures, systems and procedures support individual learning. Managers can play a bigger role to improve the feed-forward of learning by supporting individuals with good ideas to bring the ideas forward and help the process of institutionalization of goods ideas. The knowledge of particularly effective individuals could be captured in documentation available to anyone who requires it. A mentoring program would help to share the knowledge and skills of exceptional employees with others and embed their knowledge at the group and organization levels.

A primary leverage point to improve the feed-back flow of learning could be through the creation of an Electronic Performance Support System. Such a system could be designed to capture and store important information and be available on-line to those who need it, when they need it. Other opportunities to improve feed-back flows may be uncovered by the organizational audit. Programs can be designed and implemented to help managers develop abilities to identify when embedded learning is impeding learning and facilitate the removal of blockages. Managers can aid information flow by disseminating information to people who can 
benefit from it, getting the right people working on the right issues, and understanding and supporting communities of practice.

\section{Narrow the Cognition/Behaviour Gaps}

Management can be a primary leverage point for narrowing the gap between cognition and behaviour relative to learning. Blockages to behaving in line with beliefs could be caused by employees who do not believe that the learning behaviours are highly valued. If actions such as challenging the assumptions of the group, experimentation and creativity are highly -valued by the organization then managers can encourage these behaviours by rewarding them. One solution may be that managers need to demonstrate putting the beliefs into action in order for people to practice the behaviours to greater degree. 


\section{Chapter Six: Conclusions}

The purpose of this study was to assess whether educators can benefit from developing a pragmatic knowledge of organizational learning and whether a measurement instrument can help us understand how to improve organizational effectiveness through better learning processes and abilities. In particular, two research questions were examined: 1) What is the difference between organizational learning and the learning of individuals who are participants in the organization? and, 2) If we can substantiate organizational learning theoretically, can it be identified, diagnosed and leveraged?

The theoretical discussion and empirical results are highly suggestive that $\mathrm{OL}$ is more than the learning that individuals do. The appreciation for the dimension of embedded learning at the organization level and its inter-relatedness with the other levels have been good contributions to our understanding of learning in organizations. The discussion of the impact on learning of leader's beliefs and actions has also provided insight. The behaviour/cognition matrix has provided a thought-provoking concept to draw attention to the instructional strategies we use. Educators need to appreciate what the outcomes of varying degrees of cognitive and behaviour change may be and how to achieve "integrated learning".

The findings of the study challenge the mental models of corporate educators who typically believe that individual learning is a planned, observable, programmed activity. Everyday learning behaviours and conditions for learning are often not understood in terms of their significance to overall learning. We use instructional techniques that have people work in groups but it has been difficult to perceive groups and the organization as entities that learn in different ways than by purely the aggregation of individual learning. 
As a lens to collect information and determine actions to improve $O L$, the Learning Matrix and the results from the Learning Assessment Map can provide a focal point and data that we can discuss to bring greater understanding to the abstract view of organizational learning provided in the literature. The information helps us start to develop a pragmatic understanding of differences between the learning levels. The results can be bundled for analysis and prioritization in the six categories: individual, group, organization, knowledge flows, leadership and cognition. The categories help the process of deciding what action to take based on the results and how to bundle strategic programs for improvement.

Although the results for the participating organization are tentative because of the early stage of development of the tool, the results of the Learning Assessment Map strongly suggests that the greatest impact on learning is not from training and education of individuals and groups. The greatest leverage points for investing in learning for the participating organization may be: improving the organizational level as a storehouse of knowledge and as a catalyst for learning; implementing programs to enhance learning flows to utilize the knowledge and skills of individuals and groups (feed-forward) and to facilitate the development of skills and knowledge of individuals and groups (feed-back); and taking action to narrow the gap benveen behaviours and cognition relative to learning.

When the results for this administration of the Learning Assessment Map were shared with the participating organization, the managers agreed with the majority of the observations. They will use the theoretical background and the insights provided by the results in strategic planning discussions. The fact that the results "rang true" for the management group is a 
validation that the measurement of $\mathrm{OL}$ can add value to the process of developing and implementing plans to improve organizational effectiveness.

In closing, there are a few additional comments that may suggest other research opportunities as an extension of this study. The research is potentially value-added for educational administrators searching for ways to improve the effectiveness of schools. The Learning Matrix and Learning Assessment Map can help administrators broaden their understanding of their school as a learning orgnaization, identify the current strengths of the individual, group and organization levels of learning and barriers to learning that will block learning flow. The administrator can then formulate a strategy to improve OL.

The Learning Matrix and the measurement tool suggest that management of learning is not the domain of any one part of the organization. For example, one time training events or education of individuals offered through the Human Resources department will not make a significant difference in performance without the support of elements on the levels of group and organization such as: structural elements that allow the right flow of information; managers who provide support, willingness and capacity to reinforce new behaviours; behavioural evidence that certain learning beliefs are widely-held; and reward and compensation for desirable performance. The data gathered by the Learning Assessment Map can potentially lead to improvement programs that will be the responsibility of many parts of the organization. For example, improved information systems, restructuring, tracking and reporting instruments, and compensation would all be dealt with by different parts of the organization. A practical knowledge of OL helps to broaden the scope of areas in which educators can add value to organization effectiveness. We have the opportunity to influence 
learning in ways that recognize not all leaming takes place in an traditional educational setting or in the minds of individuals.

The opportunity for further exploration with the participating organization will give me a better understanding of how to implement $\mathrm{OL}$ improvement programs. The organization wants to create specific programs and track their progress. The organization plans to start by educating managers to be more aware of their influence on the flow of learning. The organization will also look for ways to increase the trust and perceived acceptance for innovation and experimentation in their culture.

The research has provided insights and given a starting point that educators in many types of organizations can use to broaden their understanding of learning, widen their span of potential influence and ultimately, improve the learning processes and patterns in their organizations. 


\section{Appendix One}

\section{Measuring Learning in Organizations}

Dear Employee,

Developing a Learning Organization is a goal of many organizations. An important step in evolving to a leaming organization is the identification of leaming patterns. This survey is designed to identify everyday patterns of learning in any organization.

\section{Please review this section before contiming with the sumey.}

The word, "Organization", is used throughout this survey. The "Organization" is defined as your division within the company. Think in terms of your division as you answer the questions, not the larger corporation.

The words, "Group" and "we", are used in the survey to refer to the people you usually work with on a daily basis.

Completion of the survey will take about 20-30 minutes. Answer the questions by circling one response. Responses range from 1 (Strongly Disagree) to 7 (Strongty Agree). Your involvement is voluntary and you may choose not to answer any question.

We are interested in your opinions and experiences. All information you provide is strictly confidential and anonymous. Your personal responses will not be identified in any way in the final reporting. Collective results will be available from your management. All returned surveys will be given to an extemal data processor for input and not analyzed individually.

If you would like to contact us directly, please call Lori Nemeth at

Your response within five days of receiving the survey is appreciated.

\section{Thank you for your participation.}

When you have completed the survey:

Put the completed survey in an inter-office envelope, attach the label provided, drop the envelope in inter-office mail. If you misplace the label, please address the envelope to: 
A. The following statements relate to the behavions of individuals in your organization. Please circle the most approprinte reyponse.

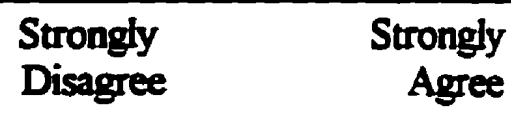

1. Individuals generate many new insights.

2. Individuals take actions that are experimental in nature.

3. Individuals are able to break out of traditional mind-sets to see things in new and different ways.

4. Individuals are able to grow through their work.

5. Individuals are aware of the critical issues that affect their work.

6. Individuals accept negative feedback without becoming defensive.

7. Individuals have a clear sense of direction in their work

8. Individuals feel a sense of accomplishment in what they do.

9. Individuals have a capacity to change and grow with the business.

10. Individuals feel a sense of pride in what they do.

11. Individuals feel a sense of ownership in what they do.

12. Individuals look for new and better ways to work.

13. Individuals are current and knowledgeable about their field of work

14. Individuals have a high level of energy at work.

15. Individuals feel confident in their work.

16. When individuals make an error they will usually try to cover it up.

17. Individuals scan the external environment (customers, suppliers, competitors, government) to assess future risks and opportunities.

18. Individuals demonstrate a high level of competency in their work.

19. The origin of most of our innovative ideas are people within the organization.

20. Individuals tend to act in their own self interest. $\begin{array}{lllllll}1 & 2 & 3 & 4 & 5 & 6 & 7\end{array}$

$\begin{array}{lllllll}1 & 2 & 3 & 4 & 5 & 6 & 7\end{array}$

$\begin{array}{lllllll}1 & 2 & 3 & 4 & 5 & 6 & 7\end{array}$

$\begin{array}{lllllll}1 & 2 & 3 & 4 & 5 & 6 & 7\end{array}$

$\begin{array}{lllllll}1 & 2 & 3 & 4 & 5 & 6 & 7\end{array}$

$\begin{array}{lllllll}1 & 2 & 3 & 4 & 5 & 6 & 7\end{array}$

$\begin{array}{lllllll}1 & 2 & 3 & 4 & 5 & 6 & 7\end{array}$

$\begin{array}{lllllll}1 & 2 & 3 & 4 & 5 & 6 & 7\end{array}$

$\begin{array}{lllllll}1 & 2 & 3 & 4 & 5 & 6 & 7\end{array}$

$\begin{array}{lllllll}1 & 2 & 3 & 4 & 5 & 6 & 7\end{array}$

$\begin{array}{lllllll}1 & 2 & 3 & 4 & 5 & 6 & 7\end{array}$

$\begin{array}{lllllll}1 & 2 & 3 & 4 & 5 & 6 & 7\end{array}$

$\begin{array}{lllllll}1 & 2 & 3 & 4 & 5 & 6 & 7\end{array}$

$\begin{array}{lllllll}1 & 2 & 3 & 4 & 5 & 6 & 7\end{array}$

$\begin{array}{lllllll}1 & 2 & 3 & 4 & 5 & 6 & 7\end{array}$

$\begin{array}{lllllll}1 & 2 & 3 & 4 & 5 & 6 & 7\end{array}$

$\begin{array}{lllllll}1 & 2 & 3 & 4 & 5 & 6 & 7\end{array}$

$\begin{array}{lllllll}1 & 2 & 3 & 4 & 5 & 6 & 7\end{array}$

$\begin{array}{lllllll}1 & 2 & 3 & 4 & 5 & 6 & 7\end{array}$

$\begin{array}{lllllll}1 & 2 & 3 & 4 & 5 & 6 & 7\end{array}$ 
21. We rarely think or act beyond the boundary of our own jobs.

22. Individuals are prepared to challenge the assumptions of the group.

23. Individuals possess the appropriate communication skills to contribute to the group process.

24. Individuals are discouraged by the resistance they receive from others when trying to effect change.

25. We are encouraged to share our ideas with others.

26. New ideas are generally accepted by members of my organization.

27. Individuals are reluctant to share their ideas with others.

28. We share new insights throughout the organization.

29. This organization captures the intelligence of its workforce.

30. Individuals understand how their work contributes to the performance of the organization.

31. We routinely communicate the lessons leamed from our past actions throughout the organization.

32. New insights get developed into improved products or processes.

33. We seem to continually "re-invent the wheel".

34. There are many good ideas that seem to go nowhere.

35. When a good person leaves this organization, we lose valuable information. $\begin{array}{lllllll}1 & 2 & 3 & 4 & 5 & 6 & 7\end{array}$

$\begin{array}{lllllll}1 & 2 & 3 & 4 & 5 & 6 & 7\end{array}$

$\begin{array}{lllllll}1 & 2 & 3 & 4 & 5 & 6 & 7\end{array}$

$\begin{array}{lllllll}1 & 2 & 3 & 4 & 5 & 6 & 7\end{array}$

$\begin{array}{lllllll}1 & 2 & 3 & 4 & 5 & 6 & 7\end{array}$

$\begin{array}{lllllll}1 & 2 & 3 & 4 & 5 & 6 & 7\end{array}$

$\begin{array}{lllllll}1 & 2 & 3 & 4 & 5 & 6 & 7\end{array}$

$\begin{array}{lllllll}1 & 2 & 3 & 4 & 5 & 6 & 7\end{array}$

$\begin{array}{lllllll}1 & 2 & 3 & 4 & 5 & 6 & 7\end{array}$

$\begin{array}{lllllll}1 & 2 & 3 & 4 & 5 & 6 & 7\end{array}$

$\begin{array}{lllllll}1 & 2 & 3 & 4 & 5 & 6 & 7\end{array}$

$\begin{array}{lllllll}1 & 2 & 3 & 4 & 5 & 6 & 7\end{array}$

$\begin{array}{lllllll}1 & 2 & 3 & 4 & 5 & 6 & 7\end{array}$

$\begin{array}{lllllll}1 & 2 & 3 & 4 & 5 & 6 & 7\end{array}$

$\begin{array}{lllllll}1 & 2 & 3 & 4 & 5 & 6 & 7\end{array}$

B. The next statements relate to the actions or work of groups. Please circle the most appropriate number for each statement.

1. Individuals know enough about the work of others to be

$\begin{array}{lllllll}1 & 2 & 3 & 4 & 5 & 6 & 7\end{array}$ able to pass on the information they need.

2. Individuals take the needs of other members of the group into account when making decisions.

3. Once the group has made a decision, individuals will support it. 
4. Group work in this organization is valuable.

5. Others in the organization co-operate with us in order to share relevant information.

6. Different points of view are encouraged in my group.

7. We have effective resolution of conflict in my group.

8. When we work in groups, ideas arise that did not occur to any one individual.

9. We do not know how to effectively work in groups.

10. When working in groups we have the right people involved in addressing the issues.

11. We share our successes with others.

12. We share our fillures with others.

13. In meetings, we are prepared to rethink decisions when presented with new information.

14. We have too many unproductive meetings.

15. In meetings, we seek to understand everyone's viewpoint.

16. Group decision-making is an important step in making organizationwide changes.

17. Group decision-making impedes progress in making organizationwide changes

18. We propose innovative solutions to organization-wide problems.

19. The decisions groups make are reflected in changes to our organizational systems and procedures.

20. No matter what we do, the organization does not seem to change.

21. In meetings, we have access to the right information to make the best decisions.

22. When making decisions for the future, we do not seem to have any memory of the past. $\begin{array}{lllllll}1 & 2 & 3 & 4 & 5 & 6 & 7\end{array}$

$\begin{array}{lllllll}1 & 2 & 3 & 4 & 5 & 6 & 7\end{array}$

$\begin{array}{lllllll}1 & 2 & 3 & 4 & 5 & 6 & 7\end{array}$

$\begin{array}{lllllll}1 & 2 & 3 & 4 & 5 & 6 & 7\end{array}$

$\begin{array}{lllllll}1 & 2 & 3 & 4 & 5 & 6 & 7\end{array}$

$\begin{array}{lllllll}1 & 2 & 3 & 4 & 5 & 6 & 7\end{array}$

$\begin{array}{lllllll}1 & 2 & 3 & 4 & 5 & 6 & 7\end{array}$

$\begin{array}{lllllll}1 & 2 & 3 & 4 & 5 & 6 & 7\end{array}$

$\begin{array}{lllllll}1 & 2 & 3 & 4 & 5 & 6 & 7\end{array}$

$\begin{array}{lllllll}1 & 2 & 3 & 4 & 5 & 6 & 7\end{array}$

$\begin{array}{lllllll}1 & 2 & 3 & 4 & 5 & 6 & 7\end{array}$

$\begin{array}{lllllll}1 & 2 & 3 & 4 & 5 & 6 & 7\end{array}$

$\begin{array}{lllllll}1 & 2 & 3 & 4 & 5 & 6 & 7\end{array}$

$\begin{array}{lllllll}1 & 2 & 3 & 4 & 5 & 6 & 7\end{array}$

$\begin{array}{lllllll}1 & 2 & 3 & 4 & 5 & 6 & 7\end{array}$

$\begin{array}{lllllll}1 & 2 & 3 & 4 & 5 & 6 & 7\end{array}$

$\begin{array}{lllllll}1 & 2 & 3 & 4 & 5 & 6 & 7\end{array}$

$\begin{array}{lllllll}1 & 2 & 3 & 4 & 5 & 6 & 7\end{array}$

$\begin{array}{lllllll}1 & 2 & 3 & 4 & 5 & 6 & 7\end{array}$ 
23. Valuable information from success or failure of past programs is not available.

24. Reward systems recognize the contribution made by groups.

C. In this section, several value statements are given. By circling the appropriate number, indicate to what extent you believe each value is widety-held in your oreanization.

1. We value creativity.

2. Experimentation is necessary for learning.

3. Making mistakes is part of leaming.

4. It is important to be open-minded.

5. It is important to feel fulfilled by your work.

6. Innovation is taking a good idea and making it happen.

7. It is important to capitalize on a good idea.

8. Individuals can make a difference.

9. Diversity is important.

10. Open communication is critical.

11. Teamwork is an essential part of organizational activity.

12. It is important to share our ideas with others.

13. Others can leam from our successes and failures.

14. To contribute to others, we need to be aware of their needs and issues. $\begin{array}{lllllll}1 & 2 & 3 & 4 & 5 & 6 & 7\end{array}$ $\begin{array}{lllllll}1 & 2 & 3 & 4 & 5 & 6 & 7\end{array}$

$\begin{array}{lllllll}1 & 2 & 3 & 4 & 5 & 6 & 7\end{array}$

1234567

$\begin{array}{lllllll}1 & 2 & 3 & 4 & 5 & 6 & 7\end{array}$

$\begin{array}{lllllll}1 & 2 & 3 & 4 & 5 & 6 & 7\end{array}$

$\begin{array}{lllllll}1 & 2 & 3 & 4 & 5 & 6 & 7\end{array}$

$\begin{array}{lllllll}1 & 2 & 3 & 4 & 5 & 6 & 7\end{array}$

$\begin{array}{lllllll}1 & 2 & 3 & 4 & 5 & 6 & 7\end{array}$

$\begin{array}{lllllll}1 & 2 & 3 & 4 & 5 & 6 & 7\end{array}$

$\begin{array}{lllllll}1 & 2 & 3 & 4 & 5 & 6 & 7\end{array}$

$\begin{array}{lllllll}1 & 2 & 3 & 4 & 5 & 6 & 7\end{array}$

$\begin{array}{lllllll}1 & 2 & 3 & 4 & 5 & 6 & 7\end{array}$

$\begin{array}{lllllll}1 & 2 & 3 & 4 & 5 & 6 & 7\end{array}$

D. The neit statements relate to the culture, strategy and vision of your organization. Please circle the number that best corresponds to your agreement with the statement.

1. Individuals understand the vision and strategy of your organization. $\quad \begin{array}{lllllll}1 & 2 & 3 & 4 & 5 & 6 & 7\end{array}$

2. Individuals are directed by the vision and strategy of the $\quad \begin{array}{lllllll}1 & 2 & 3 & 4 & 5 & 6 & 7\end{array}$ organization. 
3. Individuals have input into our strategy.

4. The organizational structure supports our strategic direction.

5. We have a strategy that positions us well for the future.

6. We have a realistic yet challenging vision for the organization.

7. We have an organizational culture characterized by a high degree of trust.

8. The organization culture could be characterized as innovative.

9. We are a "Learning Organization". $\begin{array}{lllllll}1 & 2 & 3 & 4 & 5 & 6 & 7\end{array}$

$\begin{array}{lllllll}1 & 2 & 3 & 4 & 5 & 6 & 7\end{array}$

$\begin{array}{lllllll}1 & 2 & 3 & 4 & 5 & 6 & 7\end{array}$

$\begin{array}{lllllll}1 & 2 & 3 & 4 & 5 & 6 & 7\end{array}$

$\begin{array}{lllllll}1 & 2 & 3 & 4 & 5 & 6 & 7\end{array}$

$\begin{array}{lllllll}1 & 2 & 3 & 4 & 5 & 6 & 7\end{array}$

$\begin{array}{lllllll}1 & 2 & 3 & 4 & 5 & 6 & 7\end{array}$

E. The nert questions relate to your perceptions of management's influence on your unit (i.e., your unit manager and the person he/she reports to). Please circle the number that corresponds to your reaponse

1. Management supports the learning and development of individuals. $\quad \begin{array}{lllllll}1 & 2 & 3 & 4 & 5 & 6 & 7\end{array}$

2. Management encourages experimentation and innovation.

$\begin{array}{lllllll}1 & 2 & 3 & 4 & 5 & 6 & 7\end{array}$

3. Decisions made by the management team have a strong impact on what individuals do.

$\begin{array}{lllllll}1 & 2 & 3 & 4 & 5 & 6 & 7\end{array}$

4. Decisions made by management are well-communicated to the workforce.

5. Individuals feel well served by management.

$\begin{array}{lllllll}1 & 2 & 3 & 4 & 5 & 6 & 7\end{array}$

6. Individuals feel they have input into the critical decisions made by management.

$\begin{array}{lllllll}1 & 2 & 3 & 4 & 5 & 6 & 7\end{array}$

7. Management understands the challenges facing individuals in this organization.

8. Individuals understand how what they do fits into the decisions made by management.

9. Management continually ensures that new knowledge is disseminated to all parts of the organization. 
11. The management team has articulated a clear strategic direction.

12. The management team has developed a clear vision.

13. The management team drives change in this organization.

14. Management actions support the strategy.

15. Management actions are in keeping with the stated vision.

16. Management demonstrates the leadership qualities required to excel. $\begin{array}{lllllll}1 & 2 & 3 & 4 & 5 & 6 & 7\end{array}$

$\begin{array}{lllllll}1 & 2 & 3 & 4 & 5 & 6 & 7\end{array}$

$\begin{array}{lllllll}1 & 2 & 3 & 4 & 5 & 6 & 7\end{array}$

$\begin{array}{lllllll}1 & 2 & 3 & 4 & 5 & 6 & 7\end{array}$

$\begin{array}{lllllll}1 & 2 & 3 & 4 & 5 & 6 & 7\end{array}$

$\begin{array}{lllllll}1 & 2 & 3 & 4 & 5 & 6 & 7\end{array}$

F. These statements relate to how the systems, structures and procedures of your organization influence you and your work unit.

1. Time for learning is readily available to all individuals.

2. Resources for leaming are readily available to all individuals.

3. Our systems and procedures support innovation.

4. Our policies and procedures aid individual work.

5. Cross training, job rotation and ad hoc assignments are used to develop a more flexible workforce.

6. Our compensation structure rewards individuals appropriately.

7. Our compensation structure motivates individuals appropriately.

8. Training is readily available when it is needed to improve knowledge and skills.

9. Our policies and procedures of the organization block new ideas.

10. Our organizational structure enables the right people to deal with the right problems.

11. We recruit the best people in the industry.

12. Key information is readily available through our information systems. $\begin{array}{lllllll}1 & 2 & 3 & 4 & 5 & 6 & 7\end{array}$

$\begin{array}{lllllll}1 & 2 & 3 & 4 & 5 & 6 & 7\end{array}$

$\begin{array}{lllllll}1 & 2 & 3 & 4 & 5 & 6 & 7\end{array}$

$\begin{array}{lllllll}1 & 2 & 3 & 4 & 5 & 6 & 7\end{array}$

$\begin{array}{lllllll}1 & 2 & 3 & 4 & 5 & 6 & 7\end{array}$

$\begin{array}{lllllll}1 & 2 & 3 & 4 & 5 & 6 & 7\end{array}$

$\begin{array}{lllllll}1 & 2 & 3 & 4 & 5 & 6 & 7\end{array}$

$\begin{array}{lllllll}1 & 2 & 3 & 4 & 5 & 6 & 7\end{array}$

$\begin{array}{lllllll}1 & 2 & 3 & 4 & 5 & 6 & 7\end{array}$

$\begin{array}{lllllll}1 & 2 & 3 & 4 & 5 & 6 & 7\end{array}$

$\begin{array}{lllllll}1 & 2 & 3 & 4 & 5 & 6 & 7\end{array}$

$\begin{array}{lllllll}1 & 2 & 3 & 4 & 5 & 6 & 7\end{array}$ 
13. Our information systems make it easy for individuals to share information.

14. Our organizational structure facilitates the sharing or ideas.

$\begin{array}{lllllll}1 & 2 & 3 & 4 & 5 & 6 & 7\end{array}$

15. Our information systems are "leading edge".

$\begin{array}{lllllll}1 & 2 & 3 & 4 & 5 & 6 & 7\end{array}$

16. We have systems in place that enable us to keep track of the critical issues that affect our business.

$\begin{array}{lllllll}1 & 2 & 3 & 4 & 5 & 6 & 7\end{array}$

17. We have relevant performance indicators for our business.

$\begin{array}{lllllll}1 & 2 & 3 & 4 & 5 & 6 & 7\end{array}$

18. Our organizational structure needs to be reassessed.

$\begin{array}{lllllll}1 & 2 & 3 & 4 & 5 & 6 & 7\end{array}$

19. Our physical assets are inadequate (i.e., buildings, furniture).

$\begin{array}{lllllll}1 & 2 & 3 & 4 & 5 & 6 & 7\end{array}$

G. The nest questions relate to your perceptions of how well your organization is meeting the needs of various groups.

1. We understand and meet our external customer needs.

$\begin{array}{lllllll}1 & 2 & 3 & 4 & 5 & 6 & 7\end{array}$

2. We understand and meet our internal customer needs.

$\begin{array}{lllllll}1 & 2 & 3 & 4 & 5 & 6 & 7\end{array}$

3. Employees are very satisfied working here.

$\begin{array}{lllllll}1 & 2 & 3 & 4 & 5 & 6 & 7\end{array}$

4. We provide a good return to our shareholders.

$1 \quad 2 \quad 3 \quad 4 \quad 55627$

5. Individuals are generally satisfied with their performance.

$\begin{array}{lllllll}1 & 2 & 3 & 4 & 5 & 6 & 7\end{array}$

6. Individuals are fulfilled by their work.

$\begin{array}{lllllll}1 & 2 & 3 & 4 & 5 & 6 & 7\end{array}$

H. Please answer the following questions which will help us when analyzing survey results.

1. Put a checkmark beside the words that best represent your position.

Senior Manager Manager Other

2. What is the name of your work unit within the organization? 


\title{
Appendix Two
}

\author{
Results
}

\section{Individual Level}

\begin{tabular}{|r|r|l|}
\hline 4.68 & 1.48 & Individuals generate many new insights. \\
\hline 3.82 & 1.28 & Individuals take actions that are experimental in nature. \\
\hline 4.17 & 1.39 & Individuals are able to break out of traditional mind-sets to see things in new \\
\hline 4.6 & 1.5 & Ind different ways. \\
\hline 4.85 & 1.34 & Individuals are able to grow through their work. \\
3.8 & 1.32 & Individuals accept negative feedback without becoming defensive. \\
4.53 & 1.3 & Individuals have a clear sense of direction in their work. \\
4.55 & 1.48 & Individuals feel a sense of accomplishment in what they do. \\
4.67 & 1.42 & Individuals have a capacity to change and grow with the business. \\
4.67 & 1.33 & Individuals feel a sense of pride in what they do. \\
4.36 & 1.53 & Individuals feel a sense of ownership in what they do. \\
4.84 & 1.27 & Individuals look for new and better ways to work. \\
5.09 & 1.22 & Individuals are current and knowledgeable about their field of work. \\
4.54 & 1.28 & Individual have a high level of energy at work. \\
4.88 & 1.18 & Individuals feel confident in their work. \\
5.06 & 1.32 & When individuals make an error, they will usually try to cover it up. (rev) \\
3.78 & 1.43 & Individuals scan the external environment (customer, suppliers, competitors, \\
4.94 & 1.12 & government) to assess future risks and opportunities. \\
4.94 & 1.28 & Individuals demonstrate a high level of competency in their work. \\
\hline
\end{tabular}


Group Level

\begin{tabular}{|r|l|l|}
\hline 5.43 & 1.29 & Group work in this organization is valuable. \\
4.52 & 1.41 & $\begin{array}{l}\text { Others in the organization co-operate with us in order to share relevant } \\
\text { information, }\end{array}$ \\
4.67 & 1.42 & Different points of view are encouraged in my group. \\
4.38 & 1.34 & We have effective resolution of conflict in my group. \\
4.94 & 1.21 & When we work in groups, ideas arise that did not occur to any one individual. \\
5.17 & 1.43 & We do not know how to effectively work in group. (rev) \\
4.49 & 1.24 & $\begin{array}{l}\text { When working in groups we have the right people involved in addressing the } \\
\text { issues. }\end{array}$ \\
4.84 & 1.17 & We share our successes with others. \\
4.36 & 1.25 & We share our failures with others. \\
4.79 & 1.26 & $\begin{array}{l}\text { In meetings, we are prepared to rethink decisions when presented with new } \\
\text { information. }\end{array}$ \\
4.39 & 1.61 & We have too many unproductive meetings. (rev) \\
4.67 & 1.31 & In meetings, we seek to understand everyone's viewpoint. \\
\hline
\end{tabular}

\section{Organization Level}

\begin{tabular}{|r|r|l|}
\hline 4.54 & & \\
4.63 & 1.02 & We have a strategy that positions us well for the future. \\
4.64 & 1.05 & We have a realistic yet challenging vision for the organization. \\
4.35 & 1.35 & The organization culture characterized by a high degree of trust. \\
4.6 & 1.28 & The organization culture could be characterised as innovative. \\
4.74 & 1.48 & We are a "learning Organization". \\
3.98 & 1.34 & Our information systems are "leading edge". \\
4.43 & 1.23 & We have systems in place that enable us to keep track of the critical issues that \\
4.72 & 1.21 & affect our business. \\
4.1 & 1.44 & Our organizational structure needs to be reassessed. (rev) \\
3.43 & 1.66 & Our physical assets are inadequate (i.e., buildings, furniture).(rev) \\
\hline
\end{tabular}




\section{Feed-Forward Behaviours}

\begin{tabular}{|c|c|c|}
\hline 4.24 & 1.44 & \\
\hline 4.4 & 1.43 & f our own iobs. \\
\hline & 123 & MTOU \\
\hline (.5. & 102 & Individuals nose \\
\hline 4.8 & 1.04 & $\begin{array}{l}\text { Individuals possess the } \\
\text { group process. }\end{array}$ \\
\hline 3.9 & 1.41 & $\begin{array}{l}\text { Individuals are discouraged by the resistance they receive from others when } \\
\text { trying to affect change. (rev) }\end{array}$ \\
\hline 4.6 & 1.46 & Individuals are reluctant to share their ideas with others. (rev) \\
\hline 4.62 & 1.28 & We share new insights throughout the organization. \\
\hline 4.15 & 1.42 & This organization captures the intelligence of its workforce. \\
\hline 4.84 & 1.35 & $\begin{array}{l}\text { Individuals understand how their work contributes to the performance of the } \\
\text { organization. }\end{array}$ \\
\hline 4.21 & 1.5 & the lessons learned from our past actions \\
\hline 4.63 & 1.11 & New insights get developed into improved products or processes. \\
\hline 3.74 & 1.32 & We seem to continually "re-invent the wheel". (rev) \\
\hline 3.82 & 1.49 & There are good ideas that seem to go nou \\
\hline 2.79 & 1.52 & $\begin{array}{l}\text { When a good person leaves the organization, we lose valuable information. } \\
\text { (rev) }\end{array}$ \\
\hline 3.93 & 1.49 & Individuals have input into our strategy. \\
\hline 4.05 & 1.28 & We propose innovative solutions to organization-wide problems. \\
\hline 4.38 & 1.18 & $\begin{array}{l}\text { The decisions we make are reflected in changes to our organizational systems } \\
\text { and procedures. }\end{array}$ \\
\hline 4.86 & 1.47 & No matter what we do, the organization does not seem to change. (rev) \\
\hline
\end{tabular}




\section{Feed-Back Behaviours}

\begin{tabular}{|c|c|c|}
\hline 4.58 & 27 & attion. \\
\hline 438 & 135 & \\
\hline 4.30 & כנ.1 & Individuals are directed by the vision and strategy of the organization. \\
\hline 3.29 & 1.62 & Time for learning is readily available to all individuals. \\
\hline 3.85 & 1.62 & Resources for leaming are readily available to all individuals. \\
\hline 4.01 & 1.33 & Our systems and procedures support innovation. \\
\hline 4.27 & 1.37 & Our policies and procedures aid individuals work. \\
\hline 4.07 & 1.78 & $\begin{array}{l}\text { Cross training, job rotation and ad hoc assignments are used to develop a more } \\
\text { flexible workforce. }\end{array}$ \\
\hline 3.43 & 1.95 & Our compensation structure rewards people appropriately. \\
\hline 3.38 & 1.53 & Our compensation structure motivates individuals appropriately. \\
\hline 3.99 & 1.59 & Training is readily available when it is needed to improve knowledge and skills. \\
\hline 4.51 & 1.57 & Our policies and procedures of the organization block new ideas. (rev) \\
\hline 4.24 & 1.39 & $\begin{array}{l}\text { Our organizational structure enables the right people to deal with the right } \\
\text { problems. }\end{array}$ \\
\hline 4.18 & 1.53 & We recruit the best people in the industry. \\
\hline 4.36 & 1.49 & Key information is readily available through our information systems. \\
\hline 4.35 & 1.11 & In meetings, we have access to the right information to make the best decisions. \\
\hline 4.78 & 1.31 & $\begin{array}{l}\text { When making decisions for the future, we do not seem to have a memory of the } \\
\text { past. (rev) }\end{array}$ \\
\hline 4.88 & 1.42 & $\begin{array}{l}\text { Valuable information from success or failure of past programs is not available. } \\
\text { (rev) }\end{array}$ \\
\hline 3.92 & 1.63 & Reward systems recognize the contribution made by groups. \\
\hline 4.44 & 1.38 & Our information systems make it easy for individuals to share information. \\
\hline 4.45 & 1.4 & Our organizational structure facilitate the sharing of ideas. \\
\hline 4.19 & 1.21 & $\begin{array}{l}\text { Individuals know enough about the work of others to be able to pass on the } \\
\text { information they need. }\end{array}$ \\
\hline 4.28 & 1.35 & $\begin{array}{l}\text { Individuals take the needs of other members of the group into account when } \\
\text { making decisions. }\end{array}$ \\
\hline 4.591 & 1.1 & Once the group has made a decisions, individuals will support it. \\
\hline $4.2 i$ & 1.36 & Individuals comply too easily with directives. (rev) \\
\hline
\end{tabular}




\section{Leadership Impact on Learning}

\section{Leadership}

\begin{tabular}{|c|c|c|}
\hline 4.52 & 1.39 & $\begin{array}{l}\text { Management continually ensures that new knowledge and information are } \\
\text { disseminated to all parts of the organization. }\end{array}$ \\
4.51 & 1.27 & \begin{tabular}{l} 
Management works as a team. \\
\hline
\end{tabular} \\
\hline
\end{tabular}

\section{Feed-forward Leadership}

\begin{tabular}{|c|c|c|}
\hline & 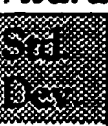 & \\
\hline 4.45 & 1.22 & The management team has articulated a clear strategic direction. \\
\hline 4.52 & 1.35 & The management team has developed a clear vision. \\
\hline 5 & 1.24 & The management team drives change in the organization. \\
\hline 4.82 & 1.18 & Management actions \\
\hline 5.15 & 1.47 & Management understands the challenges facing individuals in this organizatic \\
\hline 4.35 & 1.29 & what they do fits into the decisions \\
\hline
\end{tabular}

Feed-back Leadership

\begin{tabular}{|r|l|l|}
\hline 4.7 & 1.64 & Management supports the learning and development of individuals. \\
4.59 & 1.48 & Management encourages experimentation and innovation. \\
5.55 & 1.19 & $\begin{array}{l}\text { Decisions made by the management team have a strong impact on what } \\
\text { individuals do. }\end{array}$ \\
4.45 & 1.52 & Decisions made by management are well-communicated to the workforce. \\
4.11 & 1.42 & Individuals feel well served by management. \\
3.52 & 1.43 & Individuals feel they have input into the critical decisions made by \\
4.7 & 1.22 & Management. \\
4.67 & 1.52 & Management actions are in keeping with the stated vision. \\
\hline
\end{tabular}




\section{Performance Measures}

\begin{tabular}{|r|r|l|}
\hline 5.12 & 1.18 & We understand and meet our external customer needs. \\
4.92 & 1.21 & We understand and meet our internal customer needs. \\
3.93 & 1.4 & Employees are very satisfied working here. \\
5.04 & 1.2 & We provide a good return to our shareholders. \\
4.58 & 1.23 & Individuals are generally satisfied with their performance. \\
4.03 & 1.4 & Individuals are fulfilled by their work. \\
\hline
\end{tabular}

\section{Cognition Measures}

\begin{tabular}{|r|l|l|}
\hline 5.74 & 1.05 & It is important to capitalize on a good idea. \\
\hline 5.74 & 1.39 & Teamwork is an essential part of organizational activity. \\
5.73 & 1.25 & It is important to be open-minded. \\
5.66 & 1.56 & Open communication is critical. \\
5.58 & 1.39 & It is important to share our ideas with others. \\
5.47 & 1.48 & It is important to feel fulfilled by your work. \\
5.46 & 1.43 & Individuals can make a difference. \\
5.46 & 1.39 & To contribute to others, we need to be aware of their needs and issues. \\
5.43 & 1.16 & Innovation is taking a good idea and making it happen. \\
5.42 & 1.38 & Others can learn from our success and failures. \\
5.26 & 1.41 & Diversity is important. \\
5.15 & 1.37 & Making mistakes is part of learning. \\
4.93 & 1.4 & We value creativity. \\
4.91 & 1.35 & Experimentation is necessary for learning. \\
\hline
\end{tabular}




\section{Evidence of Ethics Approval}

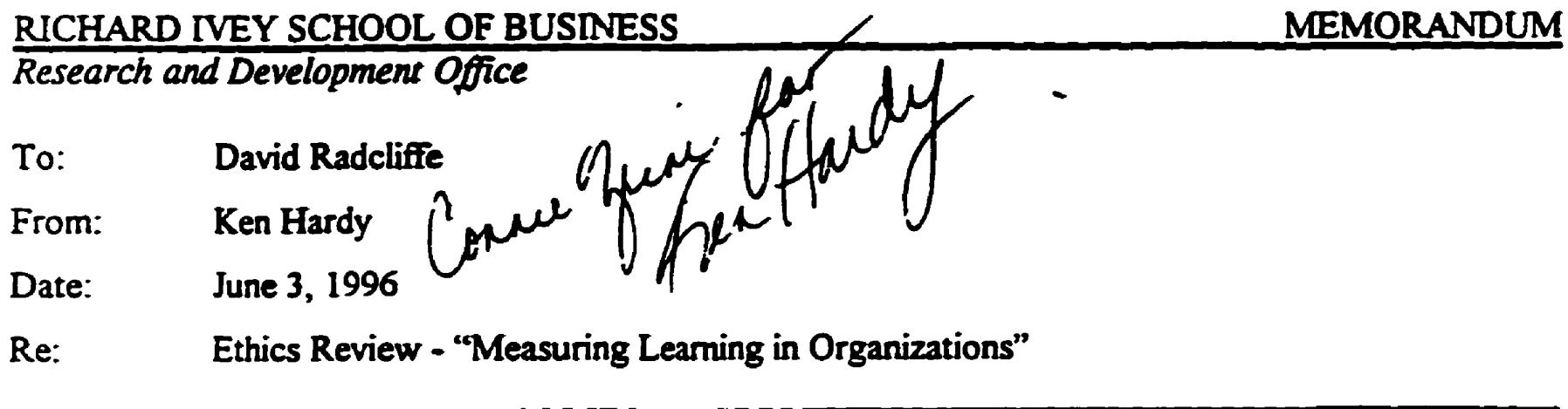

The Ethics Committee of the Western Business School has given final approval for the above mentioned submission by Lori Nemeth.

If you require further information, please contact Connie Zrini, X3018.

$\mathrm{KGH} / \mathrm{cz}$ 


\section{Bibliography}

Argyris,C. (1977). Double-Loop Learning in Otganizations. Harvard Business Review, Vol. 55, No. 5, pp 115-125.

Argyris,C. and Schon, D. (1978). Organizational Learning: A Theory of Action Perspective Mass: Addison-Wesley.

Campbell, T and Cairns, H. (1994). Developing and Measuring the Learning Organization. Industrial and Commercial Training. Vol. 20, 7. pp. 10-15.

Crossan, M. (1991). Organizational Learning: A Sociocognitive Model of Strategic Management, Thesis, The University of Western Ontario.

Crossan, M. and Guatto, T. (1996). The Evolution of Organizational Learning, Journal of Organizational Change Management. Vol. 9, 1 pp. 109-115.

Crossan, M., Lane, H., Rush, J. and White, R. (ed.)(1993). Learning in Organizations, Richard Ivey School of Business, The University of Western Ontario.

Crossan, M., Lane, H., Rush, J. and White, R. (1995). Organizational Learning - Dimensions for a Theory. International Journal of Organizational Analysis, Vol. 3, No. 4, pp 337-360.

Crossan, M., Lane, H., Tiemessen, I., and White, R. (1995). Diagnosing Organizational Learning, Working Paper Series No. 95-08, Richard Ivey School of Business.

Crossan, M., Lane, H., Rush, J. and White, R. (1994). Learning Within Organization, Working Paper Series No. 94-06, Richard Ivey School of Business.

Crossan, M., Hulland, J. (1995). Measuring Organizational Learning, Working Paper Series No. 95-29, Western Business School.

Crossan, M., Hulland, J. (1996). Measuring Organizational Learning, Richard Ivey School of Business, The University of Western Ontario.

Daft, R.L., Weick, K.E. (1984). Toward a Model of Organizations as Interpretation Systems, Academy of Management Review. Vol. 9, No. 2, pp. 284-295.

Dogson, M. (1993). Organizational Learning: A review of some literatures. Organization Strudies. Vol. 14, pp. 374 - 394.

Dixon, N. M. (1993). Organizational Learning: A Review of the Literature with Implications for Human Resource Development Professionals Human Resource Development Quarterly, Vol. 3, 1 pp. 87 - 101. 
Dixon, N. M. (1993). Organizational Learning. The Conference Board of Canada Report 111-93.

Dixon, N. M. (1994). The Organizational Learning Cycle, How We can Leam Collectively. McGraw-Hill Book Company, London.

Driver, M. (1993). Learning, Cognition and Organization. in Mary Crossan et al. Learning in Organizations, Western Business School, The University of Western Ontario.

ECLO. (1994). Learning Organization Inventory. Questionnaire sent to members.

Fiol, C.M. and Lyles, M.A. (1985). Organizational Learning. Academy of Management Review, Vol. 10, pp. 803-813.

Garvin, D.A. (1993). Building a Learning Organization. Harvard Business Review. July-Aug. pp. 78-91.

Geringer, J. and Hebert, L. (1989). Control and Performance of International Joint Ventures. Lournal of International Business Studies. Vol. 20, 2, pp. 235 - 251.

Glynn, M. A., Lant, T. K., Milliken, F.L. (1994). Mapping learning Processes in Organizations: A Multi-level Framework Linking Learning and Organizing. in Advances in Managerial Cognition and Organizational Information Processing, vol. 5, p. 43-83, JAI Press.

Griffey, S., Kelleher, M. (1995). Measuring Learning: Connecting Practice with Theory. Organizational Learning: Measuring the Reality, 1995 Annual Conference of the European Consortium for the Learning Organization, May 1995.

Huber, G.P. (1991). "Organizational learning: the contributing processes and literatures", Organization Science, Vol. 2 No. 1, pp. 88-115

Leitch, C. Burgoyne, J. (1996). Learning Organization: The Measurement of Company Performance. Best Practices - Measuring the Reality. pp. 97-120

Lei D., Hitt M.A., Bettis R. (1996). Dynamic Core Competencies Through Meta-Learning and Strategic Context. Journal of Management. Vol.22, No. 4, pp. 549-569.

McKay, D. and Mink, O. Learning About Learning, forthcoming

Meacham, J.M. (1983). Wisdom and the Contest of Knowledge: Knowing that One Doesn't Know. In D. Kuhn and J.A. Meacham (eds.), Contributions in Human Development, Vol. 8, $11-134$

Nevis, E., DiBella, A., Gould, J. (1995). Understanding Organizations as Learning Systems. Sloan Management Review. winter 1995, pp. 73 - 35. 
Nicolini, D., Meznar, M. (1995). The Social Construction of Organizational Learning: Conceprual and Practical Issues in the Field. pp. 727 - 745.

Ormrod, Jeanne (1995). Human Leaming. Prentice-Hall Inc., N.J.

Pedler, M., Burgoyne, J., Boydell, T. (1991). The Learning Company. McGraw Hill Book Company. N.Y.

Scheffler, I. (1973). Reason and Teaching. Bobbs-Merril, Illinois.

Schon, Donald A. (1975). Deutero-Learning in Organizations: Learning for Increased Effectiveness. Organization Dynamics, Vol.4, No.1, pp. 2-16.

Seely- Brown, J., Duguid, P. (1991). Organizational Leaming and Communities-of-Practice: Toward a Unified View of Working, Learning and Innovation. Organization Science. Vol. 2, No. 1, pp. 40-56

Seely- Brown, J. (1993). Presentation transcript. in Mary Crossan et al. Learning in Organizarions, Western Business School, The University of Western Ontario.

Senge, P. (1990). The Fifth Discipline: The Art and Practice of the Leaming Organization. Doubleday/Currency. N.Y.

Senge, P., Kliener, A., Roberts, C., Ross, R. Smith, B. (1994). The Fifth Discipline Fieldbook Doubleday/Currency. N.Y.

Senge, P. (1990). The Leaders New Work - Building Learning Organizations. Sloan Management Review, Vol.32, No. 1, pp. 70-23

Shrivastava, P. A. (1983). Typology of Organizational Learning Systems. Journal of Organizational Leaming Systems. Vol. 20, 1.

Simons, P.R. (1995). New Roles For HRD-Officers and Managers in Learning Organizations. Oroanizational Learning: Measuring the Reality 1995 Annual Conference of the European Consortium for the Learning Organization, May 1995.

Sinkula, J. (1994). Market Information Processing and Organizational Learning. Lournal of Marketing. pp. 35-45

Sollman, J. (1995). Measurement of the Organizational Learning Climate. Organizational Learning: Measuring the Reality. 1995 Annual Conference of the European Consortium for the Learning Organization, May. 
110

Soloman, C.M. (1994). HR Facilitates the Learning Organization Concept. Personnel Journal, Nov. pp. 56-66.

Stewart, T. A., (1996). The Invisible Key to Success Shadowy Groups Called Communities of Practice are Where Learning and Growth Happen. You Can't Control Them -- But They're Easy To Kill. Fortune Magazine, Vol. 143, No. 3, pp. 173-176.

Van Burn, M.E., Lucadamo, L. (1996). ASTD's Guide to Learning Organization Assessment instruments, American Society for Training and Development. Alexandria, Virginia.

Wexley, K, Latham, G. (1991). Developing and Training Human Resources in Organizations. Harper Collins Publishers Inc. U.K. 